

\title{
The design and development of high drug loading amorphous solid dispersion for hot-melt extrusion platform
}

Tian, Y., Jacobs, E., Jones, D. S., McCoy, C. P., Wu, H., \& Andrews, G. P. (2020). The design and development of high drug loading amorphous solid dispersion for hot-melt extrusion platform. International Journal of Pharmaceutics, 586, [119545].

Published in:

International Journal of Pharmaceutics

Document Version:

Peer reviewed version

Queen's University Belfast - Research Portal:

Link to publication record in Queen's University Belfast Research Portal

Publisher rights

Copyright 2020 Elsevier B.V.

This manuscript is distributed under a Creative Commons Attribution-NonCommercial-NoDerivs License

(https://creativecommons.org/licenses/by-nc-nd/4.0/), which permits distribution and reproduction for non-commercial purposes, provided the author and source are cited

\section{General rights}

Copyright for the publications made accessible via the Queen's University Belfast Research Portal is retained by the author(s) and / or other copyright owners and it is a condition of accessing these publications that users recognise and abide by the legal requirements associated with these rights.

Take down policy

The Research Portal is Queen's institutional repository that provides access to Queen's research output. Every effort has been made to ensure that content in the Research Portal does not infringe any person's rights, or applicable UK laws. If you discover content in the Research Portal that you believe breaches copyright or violates any law, please contact openaccess@qub.ac.uk. 


\section{The design and development of high drug loading}

2 amorphous solid dispersion for hot-melt

\section{3 extrusion platform}

5 Yiwei Tian ${ }^{1 *}$, Esther Jacobs ${ }^{1}$, David S. Jones ${ }^{1}$, Colin P McCoy${ }^{1}$, Han $\mathrm{Wu}^{2,3}$, Gavin P. 6 Andrews,

7

8

1. School of Pharmacy, Queen's University Belfast, 97 Lisburn Road, Northern

9 Ireland, UK, BT9 7BL.

2. Department of Chemical Engineering, University College London, London, UK, WC1E 7JE

3. Centre for Nature Inspired Engineering, University College London, London, UK, WC1E 7JE.

* Corresponding author: Dr. Yiwei Tian

16 Corresponding address: School of Pharmacy, Queen's University Belfast, 97 Lisburn

17 Road, Northern Ireland, United Kingdom, BT9 7BL

Tel: +442890972689 
21 KEY WORDS: amorphous; amorphous solid dispersion; thermodynamic phase

22 diagram; Flory-Huggins; hot-melt extrusion, small angle x-ray scattering 
Amorphous solid dispersion (ASD) is a formulation strategy extensively used to enhance the bioavailability of poorly water soluble drugs. Despite this, they are limited by various factors such as limited drug loading, poor stability, drugexcipient miscibility and the choice of process platforms. In this work, we have developed a strategy for the manufacture of high drug loaded ASD (HDASD) using hot-melt extrusion (HME) based platform. Three drug-polymer combinations,

31 indomethacin-Eudragit $\circledast E$, naproxen-Eudragit $\circledast E$ and ibuprofen-Eudragit $\circledast E$, were used as the model systems. The design spaces were predicted through FloryHuggins based theory, and the selected HDASDs at pre-defined conditions were manufactured using HME and quench-cooled melt methods. These HDASD systems were also extensively characterised via small angle/wide angle x-ray scattering, differential scanning calorimetry, Infrared and Raman spectroscopy and atomic force microscopy. It was verified that HDASDs were successfully produced via HME platform at the pre-defined conditions, with maximum drug

39 loadings of $0.65,0.70$ and $0.60 \mathrm{w} / \mathrm{w}$ for drug indomethacin, ibuprofen and naproxen respectively. Enhanced physical stability was further confirmed by high

41 humidity $(95 \% \mathrm{RH})$ storage stability studies. Through this work, we have 42 demonstrated that by the implementation of predictive thermodynamic 43 modelling, HDASD formulation design can be integrated into the HME process 44 design to ensure the desired quality of the final dosage form. 
47 Poor aqueous solubility and subsequent limited bioavailability of many active pharmaceutical ingredients (APIs) is a significant issue in the current pharmaceutical industry with approximately, $90 \%$ of new chemical entities in the development pipeline characterised as poorly water-soluble compounds (Kalepu and Nekkanti, 2015). New, sophisticated formulation strategies have been implemented, of which, the amorphous form has proved to be a promising strategy (Repka et al., 2018). The amorphous form exists as a higher energy state,

54 due to the lack of long range order, resulting in increased free energy level and molecular mobility compared to their crystalline counterparts, thus, provides a desirable route to increase solubility and dissolution performances (Hancock and Zografi, 1997). To capture these advantages, amorphous solid dispersion (ASD) has been widely utilised. The concept of solid dispersions was first proposed in 1960s where the drug molecule is homogenously distributed within a suitable carrier(s), typically a polymer-based material. to improve its physical stability.

61 This approach has enabled a number of marketed products with significant 62 bioavailability enhancement (Zhang et al., 2018). Noticeable progresses may also 63 be highlighted for the development of fix-dose combination products, such as $64 \mathrm{kalydeco}^{\circledR}, \mathrm{ORKAMBI}^{\circledR}$, symdeco ${ }^{\circledR}$ and trikafta ${ }^{\mathrm{TM}}$, where the efficacy of the main compound ivacaftor was successfully enhanced by amorphous solid dispersion strategy (FDA, 2019a, 2019b, 2015, 2012).

67 Despite the successes achieved in exploration of ASD for enabling formulation 68 development, majority of excipient selections are still based on trial-and-error 69 methodologies with a handful of tried tested polymeric systems (Zhang et al., 
2018). We are still deficient in selecting of excipients for a given drug molecule to be formulated into a stable ASD, particularly with the integration of various manufacturing technologies, such as spray drying, hot-melt extrusion or cryomilling. Several parameters are proposed to be influential for the stability of ASDs, such as; glass transition temperature, molecular mobility, hydrogen-bonding interactions, ionic interaction and other non-specific interactions (Anderson, 2018; Mistry et al., 2015; Quinteros et al., 2008; Song et al., 2015). However, it is still not certain what manufacturing technology is the most suited for a given drug-polymer combination at various process conditions. For example, high drug loading amorphous solid dispersion (HDASD, drug loading $>50 \% \mathrm{w} / \mathrm{w}$ ), may offer numerous advantages such as reduce the dose size, pill burden and increase the therapeutic compliance, in addition to the enhanced solubility of the amorphous system (Alshahrani et al., 2015; Dedroog et al., 2019). However, HDASD system has not been widely explored due to the potential stability issues. When the drug weight fraction increases, associated processability, inhomogeneity and potential phase separation will undoubtedly affect the quality and performances of the final product. Spray drying and cryo-milling, widely recognising as the preferred techniques for these HDASD systems, are possessed with various limitations (Caron et al., 2011; Tian et al., 2014).

Quality by Design (QbD) aiming to improve the integration of pharmaceutical formulation design and product realisation leads itself into the area of predictive science. The implementation of fundamental principles and data-driven digital frameworks using in silico methods, such as, thermodynamic modelling, molecular dynamic/metadyanmic simulation and machine learning, will unquestionably improve the productivity of quality-orientated research and development for the 
Schammé et al., 2018; Tian et al., 2013). This field of cross-disciplinary research between advanced therapeutics, computational tools and manufacturing technologies under the umbrella of QbD based digital frameworks will ultimately transform the amorphous formulation design and process into a new field of

101 predictive science. Subsequently, we believe that the specific knowledge and expertise will be combined to develop reliable amorphous formulation and process design tools for quality and rapid realisation of advanced therapies in the

104 foreseeable future (Dadou et al., 2020). Therefore, the development of digital

105 framework based on both thermodynamic and kinetic principles for drug106 polymer combinations integrated with specific manufacturing techniques will be 107 vital for this industry.

109 Here, we have investigated the interesting properties of one particular category of

110 amorphous solid dispersion for the formation of HDASD via hot-melt extrusion

111 platform, where strong intermolecular interaction between drug and polymer can

112 provide the main mechanism for amorphisation during high temperature 113 processing. This type of drug-polymer combination has been reported for 114 amorphous systems such as drug lapatinib with HPMCP (Araujo et al., 2017) and 115 drug naproxen with Eudragit $®$ E (Ueda et al., 2015). A significant increase in the 116 drug loading and amorphous stability is commonly reported for these systems.

117 We suggest that the formation of strong intermolecular interaction, such as strong 118 hydrogen-bonding or ionic interaction, should be considered as one of the key 
119 principles for formulation design based on the HME platform. High drug loading 120 capacity, improved processability and amorphous stability and reduced drug 121 thermodegradation may be achieved through this principle. In this study, the 122 thermodynamic aspects of formulation design integrated with HME platform were 123 investigated, where the weak acidic drugs (indomethacin, ibuprofen and 124 naproxen) with amorphous polymeric carrier Eudragit ${ }^{\circ}$ E (EPO) were 125 considered as the suitable combinations. The thermodynamic phase diagrams for 126 three HDASD systems were constructed and utilised to guide the design of the hot127 melt extrusion process. The processability and storage stability of HDASDs were 128 further investigated using various conventional and advanced analytical 129 techniques. 


\subsection{Materials}

133 Indomethacin (IND), naproxen (NPX) and ibuprofen (IBU) with a purity of 99\% 134 were purchased from Sigma Aldrich (Irvine, UK) and Kemprotec (Kent, UK).

135 Polymer Eudragit@ E (EPO) is a cationic copolymer based on dimethylaminoethyl 136 methacrylate, butyl methacrylate, and methyl methacrylate with a ratio of 2:1:1, 137 was generously donated by Evonik GmbH (Darmstadt, Germany). The chemical 138 structures of the polymer and drugs are shown in Figure 1 and the 139 physicochemical properties of these substances used in this study are summarised 140 in Table 1.

\section{$141 \quad 2.2$ Methods}

\subsubsection{Physical mixture preparations}

143 Drug and polymer mixtures with different compositions were firstly mixed using 144 a mortar and pestle followed by a ball mill mixer (Retsch, model MM200, 145 Germany). In a typical procedure, drug and polymer powder sample totalling $146500 \mathrm{mg}$ was milled inside the ball mill mixer with two stainless steel ball at $20 \mathrm{~Hz}$, 147 except for IBU where $15 \mathrm{~Hz}$ was used. A high milling frequency would normally 148 result a fully amorphous IBU samples up to $0.5 \mathrm{w} / \mathrm{w}$. A pre-defined milling time of 149 two minutes was chosen which was subsequently followed by a two-minute 150 interval. This procedure was repeated to a maximum of up to ten mill-stop cycles 151 (max 20-minutes mill time). The ball-milled samples were subjected to a range of 152 thermal analyses for the construction of phase diagram.

\section{$153 \quad$ 2.2.2 Temperature dependent small angle/wide angle x-ray scattering}


154 The solid-state properties of ball-milled samples and the dissolution/melting

155 behaviours of crystalline drug into the polymeric matrix as a function of 156 temperature were analysed using a small angle/wide angle x-ray scattering 157 (SAXS/WAXS, Ganesha 300XL, Xenocs, France). Powerful microfocus x-ray was 158 generated from a copper source with a motorised collimation system of 4-blad 159 single crystal slits. Movable solid-state photon-counting detector (PILATUS 300K, 160 Dectris AG, Switzerland) was mounted on an uninhibited transverse rail alone the 161 beamline. A total 1.4-meter movement on the detector allows for instant 162 interchange between SAXS and WAXS configurations. The temperature control of 163 the sample was realised by a modified Linkam stage vertically installed inside the 164 vacuum chamber. The SAXS/WAXS system was carefully calibrated using 165 lanthanum hexaboride and validated again before each measurement. In a typical 166 temperature-dependent SAXS/WAXS experiment, a ball milled sample $(\sim 20$ 167 milligrams) was packed in an envelope of aluminium foil, secured on the centre of 168 the heating plate on Linkam stage, and was then subjected to a heat-cool-heat 169 cycle similar to the differential scanning calorimetry experiment. The sample was 170 heated from $25^{\circ} \mathrm{C}$ to $160^{\circ} \mathrm{C}$ at rate of $5^{\circ} \mathrm{C} / \mathrm{min}$, then fast cooled to $-40^{\circ} \mathrm{C}$ at rate of $17140^{\circ} \mathrm{C} / \mathrm{min}$. A second heating procedure was conducted from $-40^{\circ} \mathrm{C}$ to $160^{\circ} \mathrm{C}$ at rate 172 of $5{ }^{\circ} \mathrm{C} / \mathrm{min}$. The WAXS was collected every 60 seconds at exposure time of 30 173 seconds during the heat-cool-heat cycle. SAXS was also collected on selected 174 samples with 600 seconds of exposure time at key temperature points.

\section{$175 \quad 2.2 .3$ Hot-melt extrusion}

176 Hot-melt extrusion of drug-polymer physical mixtures were conducted using $17710 \mathrm{~mm}$ diameter co-rotating twin-screw extruder (Rondol microlab, France). Drug 
and polymer premixes at defined ratios were firstly prepared using mortar and

179 pestle, then fed into the extruder using a twin-screw powder feeder at a constant 180 rate. The process conditions (screw speed and temperature) for extrusion were 181 selected based on the phase diagrams (solubility curve) constructed within this 182 study (Table 2).

\subsubsection{Thermal analysis}

184 Power compensation differential scanning calorimetry (DSC8000, Perkin Elmer, 185 UK) was used throughout to study the physical properties of drug and polymer 186 systems before and after HME process. Nitrogen was used as the purge gas for low 187 speed scanning $\left(1-50^{\circ} \mathrm{C} / \mathrm{min}\right)$; helium gas was used for high speed scanning $(\geq$ $188100^{\circ} \mathrm{C} / \mathrm{min}$ ). A 5-10 mg powder sample was packed into an aluminium pan with 189 a lid. A pinhole was made in the lid to allow moisture to escape. Before conducting 190 the experiments, all ball-milled samples were dried in a vacuum oven for at least 19124 hours. Melting depression experiments were conducted at heating rate of $1921{ }^{\circ} \mathrm{C} / \mathrm{min}$ from $-40{ }^{\circ} \mathrm{C}$ to $200^{\circ} \mathrm{C}$. The endpoint of the melting endothermic peak was 193 calculated from the intercept point of the endothermic trace and the post-melting 194 baseline. Given that the drug-polymer particle surface interaction is a critical 195 requirement for melting point depression experiments, different milling cycles 196 were tested to achieve the optimal depression results. The choice of optimal 197 milling time for preparing the physical mixtures was reported in our previous 198 work (Donnelly et al., 2014; Tian et al., 2013).

199 For identification of glass transition temperatures for HDASDs immediately after 200 HME processing, freshly prepared samples were cut into small pieces and placed 
directly into the DSC pan, a scan rate of $10^{\circ} \mathrm{C} / \mathrm{min}$ was used across a temperature

202 range between -50 to $180^{\circ} \mathrm{C}$.

203 To validate the phase separation in IBU-EPO HDASD, high scanning rate was also

204 used $\left(100{ }^{\circ} \mathrm{C} / \mathrm{min}\right)$. The freshly prepared HDASD was first held at various 205 conditions relevance to the theoretical spinodal boundary of the system for 206 prolonged period, then subjected to a quench-cooling and fast scanning 207 procedure. The temperature ranges were chosen between -50 to $100^{\circ} \mathrm{C}$ for IBU 208 samples. It is noted that only IBU-EPO was suitable for this study, because the 209 predicted spinodal boundary was above the melting temperature and below the 210 thermal degradation temperature of IBU. For IND-EPO and NPX-EPO systems, the 211 predicted spinodal boundaries were both above the thermal degradation 212 temperature of the drugs.

213 Thermogravimetric analysis (TGA) was also employed to assess the thermal

214 degradation temperature of the drugs and polymer EPO. In a typical procedure, 215 small amount of sample was loaded to an open aluminium pan after initial taring 216 step, subjecting to a heating process from room temperature to $250{ }^{\circ} \mathrm{C}$ at a rate of $21710^{\circ} \mathrm{C} / \mathrm{min}$. The onset temperatures of any significant weight loss $(>10 \% \mathrm{w} / \mathrm{w})$ for 218 drugs and polymer EOP were recorded.

2.2.5 Attenuated total reflectance Fourier-transform infrared spectroscopy 220 (ATR-FTIR)

221 Analysis on the drug-polymer interactions of ASDs were conducted using ATR222 FTIR spectroscopy (Spectrum 2, Perkin Elmer, UK). Extruded samples (outside 223 and cross section) were directly placed on the ATR stage and spectrum range of $2244000-650 \mathrm{~cm}^{-1}$ was collected based on $4 \mathrm{~cm}^{-1}$ resolutions, 64 runs. 


\subsubsection{Atomic force microscopy (AFM)}

226 The NaioAFM (Nanosurf, Switzerland) instrument was used to obtain topographic 227 and phase images, allowing calculation of the surface roughness of the solid 228 dispersions. Samples of extrudate were softened immediately after HME between 229 two flat glass slides and then cooled on metal block. The slides were then carefully 230 removed, and the solid sample was placed on the sample holder. Both topographic 231 and phase images were generated with the instrument operating in dynamic mode 232 using a Tap 190Al-G cantilever (BudgetSensors, Bulgaria). Image sizes were 10x10 $233 \mu \mathrm{m}$ or $25 \times 25 \mu \mathrm{m}$, taken at a speed of 0.8 seconds per line. Additional parameters 234 were varied depending on each sample and optimum sensitivity. The setpoint of 235 the cantilever was varied from $50 \%$ to $60 \%$ of the free vibrational amplitude, 236 which was varied from 200-1000 mV. Nanosurf Naio software was used to control, 237 obtain the data and Image J was used to further analyse the images.

\subsection{7 microRaman Spectroscopy}

239 The recrystallisation of the drug from HDASDs during high humidity storage study 240 were studied using a RamanStation R3 (Avalon, Instruments, Belfast, UK) coupled 241 with a RamanMicro 300 Raman microscope (PerkinElmer, Waltham, MA, USA) 242 with objectives at various magnifications $(\sim 1.25 \mu \mathrm{m} /$ pixel $)$. A laser source of 785 $243 \mathrm{~nm}$ was used and the Raman scattering of the samples was collected between $2443200-400 \mathrm{~cm}^{-1}$ using an acquisition time of $20 \mathrm{~s}$ at resolution of $2 \mathrm{~cm}^{-1} \mathbf{2} . \mathbf{2} .8$ 245 Statistical Analysis

246 The statistical analysis for the effects of temperature on F-H interaction 247 parameters for all three drug-EPO combinations was carried out using Kruskal248 Wallis one-way ANOVA followed by Tukey-Kramer post hoc tests; $p<0.05$ was 
considered as significant. For comparison of the spectra from microRaman

250 chemical mapping and surface roughness of the freshly extruded samples (AFM),

251 a two-tailed t test was performed $p<0.05$.

3. RESULTS AND DISCUSSIONS:

253

\subsection{In situ temperature dependent SAXS/WAXS analysis}

254 Small angle/wide angle x-ray scattering has the capacity to provide the spatial

255 distribution of the dynamic features of a particle (small molecules, peptides and

256 proteins) at nano/micro-scale ranges. It has suggested that strong intermolecular

257 interactions can drive the formation of amorphous system under gentle mixing

258 and moderate heating (Dave et al., 2007). Thus, in this study, it would be of

259 significant interests to directly observe the temperature dependences of $\mathrm{x}$-ray

260 scattering pattern for the crystalline drugs (IND, NPX and IBU) in the presence of

261 polymeric carrier. In general, the dissolution of the crystalline drug into polymeric

262 matrix can result in the decrease of scattering intensity in the WAXS graph and

263 eventually, completely loss of the well-defined scattering pattern (Figure 2).

264 Examples of 3D Bragg's peak for the physical mixtures (three drugs at $0.7 \mathrm{w} / \mathrm{w}$ )

265 as a function of temperature are shown in Figure 2 with WAXS scattering graphs

266 provided at four key temperature points. Due to the strong intermolecular

267 interactions between drugs and the polymeric carrier EPO, a gradual decrease in

268 the intensity of Bragg's peaks associated with crystalline component can be

269 observed with increased temperatures.

270 For example, in IND-EPO physical mixtures, the temperature for complete

271 dissolution of $0.7 \mathrm{w} / \mathrm{w}$ IND was recorded at 125 to $130{ }^{\circ} \mathrm{C}$ which is approximate

$27230^{\circ} \mathrm{C}$ lower than the melting temperature of pure IND (DSC, $160^{\circ} \mathrm{C}$ ). Whilst, for 
273 NPX-EPO and IBU-EPO systems containing $0.7 \mathrm{w} / \mathrm{w}$ drug loading, the

274 solubilisation temperatures were also recorded at $120-125^{\circ} \mathrm{C}$ and $50-55{ }^{\circ} \mathrm{C}$

275 respectively (Figure $2 \mathrm{~b}$ and $\mathrm{c}$ ). This information is particularly useful for the

276 design of hot-melt extrusion process, where a fully amorphous solid dispersion

277 can be generated at conditions that are i) significantly lower than the melting of

278 the crystalline drug (e.g. $30^{\circ} \mathrm{C}$ lower in IND-EPO case); ii) at much high drug

279 loadings ( $\sim 0.7 \mathrm{w} / \mathrm{w}$ for IND-EPO system). The unwanted thermodegradation

280 associated with melting of the drug may be completely avoided since the

281 amorphisation of crystalline drug is driven by the dissolution rather than melting.

282 The in situ temperature dependent SAXS/WAXS analysis (complementary to DSC)

283 can also be used to provide a very direct observation at conditions that can be

284 related to the hot-melt extrusion platform (Sylvie, Tencé-Girault et al., 2019).

\subsection{The drug-polymer temperature-composition phase diagram}

286 Flory-Huggins theory (F-H), first established to estimate the miscibility of solvent-

287 polymer system, has now been expanded to many areas. There have been several

288 published drug-polymer binary systems employed using the Flory-Huggins theory

289 to investigate the level of drug-excipient interactions, from drug-solvent activity

290 derived interaction to drug-small molecule interaction and full temperature-

291 composition drug-polymer phase diagram (Huang et al., 2017; Keen et al., 2014;

292 Lin and Huang, 2010; Pajula et al., 2010; Tian et al., 2018, 2015). The

293 implementation of this classic theory in predicting the miscibility of small

294 molecules within macromolecular matrices has provided an simple and important

295 route for ASD design (DiNunzio et al., 2010). The integration of this classical

296 theory into the formulation design and process development based upon selected 
297 advanced process technologies would have undoubtedly offered great

298 advancement for the future of pharmaceutical manufacturing (Badman and Trout, 299 2014).

300 For an informative design of ASD based on hot-melt extrusion for all three model 301 drugs, small scale DSC based F-H approach to construct the temperature302 composition phase diagram was used. Through the ball milling process, a range of 303 uniform drug-polymer physical mixtures at various ratios were prepared. 304 Although, the selection of optimum ball-milling time has been previous discussed, 305 the resultant physical mixtures were deemed not suitable for the systems in this 306 study. Particularly for drugs with low glass transition temperature in its 307 amorphous state (IBU and NPX), a rubber mixture was usually obtained after a 308 very short period of milling. For example, for $0.5 \mathrm{w} / \mathrm{w}$ IBU-EPO system, the 309 physical mixture can be converted to full amorphous within only 10 minutes of 310 ball-milling at frequency of $15 \mathrm{~Hz}$ (confirmed by DSC and SAXS/WAXS, Figure 3). 311 Therefore, to achieve sufficient experimental points from the DSC measurement 312 for construction of thermodynamic phase diagram, the drug/polymer ratio was 313 selected from $0.95-0.7 \mathrm{w} / \mathrm{w}$. An example of the DSC thermogram for the IND-EPO 314 system is shown in Figure 4. For all three EPO based systems, melting endpoint 315 was not observed at a drug-polymer ratio lower than $0.7 \mathrm{w} / \mathrm{w}$. Nevertheless, a 316 quick estimation of the drug-EPO interaction parameters for all three drugs at 317 multiple compositions may be obtained with a minimum four experimental 318 points. A plot of interaction parameter, $\chi$, versus temperature for these systems 319 were shown in Figure 5a. The fitting constants at selected temperature regions 320 were obtained for IND-EPO, NPX-EPO and IBU-EPO with goodness of fit ranging 321 from $0.93,0.94$ to 0.97 respectively. The obtained interaction parameter constants 
for all three systems are summarised in Table 3. It should be highlighted that, from

323 all the published phase diagrams for various drug-polymer combinations, an

324 upper critical solution temperature (UCST) where a positive B and a negative A

325 were obtained for the drug-polymer interaction parameters (Lin and Huang, 326 2010; Marsac et al., 2009, 2006; Tian et al., 2018, 2013; Zhao et al., 2010). Thus, it

327 was very interesting to observe that a concave spinodal profile was obtained for 328 all three HDASD systems $(\mathrm{B}<0$ and $\mathrm{A}>0$ ) indicating the lower critical solution 329 temperature (LCST) behaviour (Table 3). Such behaviour has been observed for 330 many temperature responsive polymer-water systems where a polymer solution 331 to gel transition can be observed as the temperature increases (Jones, 2004; Mori 332 et al., 2010). Similar behaviours were also reported in polymer-polymer mixtures 333 (Kapnistos et al., 1996; Meredith and Amis, 2000). However, it is to our 334 knowledge, a LCST behaviour for drug-polymer binary ASD was rarely reported 335 in the literature so far apart from the combination of carbamazepine-AFFINISOL ${ }^{\mathrm{TM}}$ 336 (Huang et al., 2016). All three systems IND, NPX and IBU with polymer EPO have 337 exhibited LCST behaviour with $\mathrm{B}<0$ and $\mathrm{A}>0$ at the experimental temperature 338 range. As the temperature decreases, the experimental values for the $\chi$ became 339 more negative suggesting a stronger drug-polymer interaction and increased 340 drug-polymer miscibility at lower temperature range.

341 Furthermore, it should also be highlighted that the values of F-H interaction 342 parameter constants (B and A) of the three drug-EPO systems were very different 343 from the previously published systems (Tian et al., 2014). In all our previously 344 published drug-polymer systems such as felodipine-HPMCAS, felodipine-Soluplus 345 and felodipine-PVP, weaker intermolecular interactions were proposed at high 346 temperatures (close to the melting point of the drug) resulting a positive B and 
negative A values. The value of B highly depends on the strength of drug-polymer

348 interaction where stronger felodipine-polymer interaction normally results a 349 smaller B value (felodipine-PVP). Therefore, the miscibility ranking between three 350 polymers with neutral drug felodipine was suggested to be PVP > Soluplus > 351 HPMCAS (Tian et al., 2014). The F-H interaction parameter $\chi$ is assumed to be 352 consisted of enthalpic term (B) and entropic term (A) fitting constants (Rubinstein 353 and Colby, 2003). In comparison to weak hydrogen-bonding based ASDs, strong 354 intermolecular interactions between drugs IND, NPX and IBU and polymer EPO 355 were suggested. Therefore, it is perhaps not surprised that the change from a 356 positive B to a negative B value may be due to the negative enthaplic contributions 357 to the system. The exact mechanisms of such strong drug-polymer interaction 358 between a weakly acidic drug with weakly basic polymer or vice versa in a non359 aqueous environment should be further investigated, particularly for the 360 application of HME platform (Mistry et al., 2015; Ueda et al., 2015). Indeed, similar 361 negative enthalpic contribution to the mixing of the system has been widely 362 discussed and utilised for the formation of molten salts, ionic liquids or eutectic 363 mixtures (Dave et al., 2007; Emel'yanenko et al., 2007).

364 With the interaction parameter constants for all three drug-EPO systems obtained 365 at various temperatures, the maximum drug solubility in polymer EPO may be 366 approximated. As expected, with a strong enthalpic contribution from the drug367 EP0 systems, large drug solubility values in polymer were predicted for all three 368 drug-EPO systems (Figure 6). The solid-liquid curves represent the extrapolation 369 of dissolution/melting endpoints for drug IND, NPX and IBU with polymer EPO 370 based on the temperature-dependent interaction parameters. The experimental 371 glass transition temperatures for all three HDASDs at various compositions are 
summarised within the graphs. The theoretical glass transition temperatures

373 were calculated using Gordon-Taylor model (Baird and Taylor, 2012). The

374 theoretical spinodal curves for IND-EPO, NPX-EPO and IBU-EPO derived from the

375 temperature-dependent interaction parameters $(\chi)$ are also plotted in the graphs

376 (Figure 6).

377 Considering the previously published drug-polymer phase diagrams, we clearly 378 observe a significant increase on the predicted solubility values of drug IND, NPX

379 and IBU with the polymer EPO. Approximate $0.63 \mathrm{w} / \mathrm{w}$ for IND-EPO, $0.473 \mathrm{w} / \mathrm{w}$ 380 for NPX-EPO and $0.55 \mathrm{w} / \mathrm{w}$ for IBU-EPO were predicted as the maximum drug 381 solubility in polymer EPO at temperature $20^{\circ} \mathrm{C}$. A gradually increase on the 382 maximum drug solubility within EPO can also be observed for all three drugs with 383 elevated temperatures, however such a change was not as dramatic since the 384 inverse contributed of the entropic term (A). The predicted solubility values for 385 all three drugs within polymer EPO at several critical temperatures were 386 summarised in Table 4. Similar high drug-polymer solubility has also been 387 reported in literature when a strong interaction was proved to be the main cause. 388 For example, Mistry et al. (2015) has discussed that the strong ionic interactions 389 between weakly basic drug ketoconazole and polymer poly (acrylic acid) can be 390 probed by both infrared and solid-state NMR (Mistry et al., 2015). The strong 391 drug-polymer interaction has also resulted a very high drug solubility value (0.6 $392 \mathrm{w} / \mathrm{w}$ ). Ueda et al. (2015) have also reported a high solubility for weakly acidic drug 393 NPX in cationic polymer EPO (Ueda et al., 2015). A crystallisation was observed 394 for NPX only when the drug loading was increased to $0.7 \mathrm{w} / \mathrm{w}$ or more. 


\subsection{The importance of phase diagram for QbD of amorphous solid dispersion}

397 To accommodate the needs of emerging pharmaceutical formulations, there is a 398 continuous requirement for parallel innovation in process development and 399 quality control/assurance of the final drug products. In response, the ICH and FDA 400 released Quality by Design (QbD) frameworks to facilitate the implementation of 401 digital innovation in the pharmaceutical industry. QbD allows quality to be built 402 into the formulation/process design in a predictive manner. In order to 403 successfully implement the QbD framework, the consideration of specific process 404 platform must be integrated into the Design Space. It is critical to be aware that 405 the crystalline drug solubility and amorphous drug miscibility with amorphous 406 polymer are two separate definitions. Particularly, when the second component 407 polymer is a long chain macromolecule where the dynamic aspect of phase 408 separation can be extremely slow and highly temperature/environment 409 dependent. In most scenarios, ASDs are produced at higher temperature or 410 solvent-assisted environment using various process platforms. The amorphous 411 drug is kinetically "trapped" in a non-equilibrium state attributing to both the 412 drug-polymer interaction and other kinetic factors related to both polymeric 413 carrier and preparation method (Paudel et al., 2012). Hence, most experimental 414 results show significantly higher apparent drug miscibility with polymeric carrier 415 than the predicted thermodynamic solubility. It is imperative that we can access 416 the kinetic behaviours of the "trapped" non-equilibrium state and relate it to the 417 physical stability of ASD systems through the identification of the miscibility 418 curve. The thermodynamic miscibility curve for the system can be predicted by 419 the phase diagram as the liquid-solid line, whilst, the binodal and spinodal curves 420 are together defined as the metastability boundary between one phase 
421 amorphous state and amorphous-amorphous phase separation (AAPS) (Luebbert

422 et al., 2017; Tian et al., 2019). The position of AAPS in relation to the 423 thermodynamic liquid-solid curve will certainly provide vital information on the 424 kinetic stability of the system (Tanaka and Nishi, 1989). An illustration of three 425 possible positions for spinodal curves in relation to the liquid-solid line is 426 postulated in Figure 7 for the LCST behaviours.

427 The position of spinodal curve to the liquid-solid curve can strongly affect the 428 kinetics of amorphous-amorphous phase separation (Tian et al., 2015). The 429 verification of these positions will provide significant advances to the 430 understandings of stability of ASD systems. Luebbert et al., (2018) recently 431 reported a phase diagram (constructed by Perturbed-Chain Statistical Associating 432 Fluid Theory) exemplified as UCST behaviour with AAPS inserted through the 433 solid-liquid curve (Luebbert et al., 2018). An AAPS was evidenced at high 434 temperatures that are well above the melting point of the drug. Purohit and Taylor 435 also reported a study using high spatial resolution atomic force microscopy 436 techniques to probe the AAPS in freshly prepared ASDs, nano-scale spherical 437 domains were obtained on the surface of ASD films representing a classical 438 binodal pattern within the phase diagram (Purohit and Taylor, 2015). In 439 comparison, we are reporting a LCST behaviour for all three HDASD systems, IND440 EPO, NPX-EPO and IBU-EPO, where the estimated positions for binodal, spinodal 441 and solid-liquid curves may be described by Figure 7. From the theoretical point 442 of view, a thermodynamic stable drug-EPO amorphous system without the 443 potential of AAPS (temperature dependent) is indeed possible at this LCST 444 scenario, particularly for drug loading below $0.5 \mathrm{w} / \mathrm{w}$. For example, a red dot is 445 used to illustrate a condition for LCST behaviour. The position is sitting below the 
446 spinodal curve meaning the system will remain one phase during HME process. In

447 addition, the position is sitting outside of the liquid-solid line indicating a lower

448 free energy level for the ASD in comparison to the crystalline system. Therefore, 449 with suitable mechanical energy input to overcome the viscosity barrier, the 450 crystalline drug-polymer physical mixture at this condition will be converted into 451 a homogenous ASD without AAPS.

452 To validate the phase diagram and the position of spinodal demixing, the IBU-EPO

453 system was chosen due to the reason that predicted spinodal demixing region was 454 well below the temperatures of thermodegradation for both components. For 455 IND-EPO and NPX-EPO systems, the predicted spinodal demixing regions were 456 above their thermodegradation temperatures, thus, experimental validation was 457 not conducted (Figure 6). A physical mixture of $0.5 \mathrm{w} / \mathrm{w}$ IBU to EPO was prepared 458 as described in method section followed by quench-cooling to form a 459 homogeneous ASD. The freshly prepared $0.5 \mathrm{w} / \mathrm{w}$ IBU-EPO ASD sample was then 460 subjected to annealing experiments at two temperatures, $70{ }^{\circ} \mathrm{C}$ and $110^{\circ} \mathrm{C}$. These 461 two temperatures ( $\mathrm{T}_{\text {annealing }}>\mathrm{T}_{\mathrm{m}}$ of IBU) were identified as one-phase amorphous 462 region and AAPS region for system $0.5 \mathrm{w} / \mathrm{w}$ IBU-EPO respectively (Figure 6c). 463 Through the characterisations of PLM and microRaman chemical mapping, an 464 AAPS ASD was obtained after annealed at $110{ }^{\circ} \mathrm{C}$ for 24 hours, whilst the ASD 465 stayed homogeneous after annealed at $70{ }^{\circ} \mathrm{C}$ for similar time-scale (Support 466 Information Figure S1).

\section{3.4 In situ formation of HDASDs via HME}

468 With the guidance from thermodynamic phase diagram, it was possible to design 469 the HME process for all three HDASDs. The exact process conditions and initial 
crystalline drug loadings are presented in Table 2. The location of these HDASDs

471 were also marked in the phase diagrams in Figure 6. In each drug-EPO

472 combinations two drug loadings were selected to be in the one-phase amorphous

473 region and one drug loading was selected to be near the crystalline region. The

474 extrusion process temperatures were chosen to be below the melting points of the

475 parent crystalline drug but above the glass transition of the polymer EPO as

476 guided by the phase diagrams.

477 The freshly prepared extrudates were then characterised using DSC and ATR-FTIR

478 and directly compared with the results collected from the physical mixtures (PM)

479 and ASDs prepared by quench-cooled method (QCPM). A similar trend was

480 obtained for the thermograms of all three drug-EPO systems, outlining the in situ

481 formation of one-phased HDASDs by HME at pre-defined conditions predicted by

482 phase diagrams (Figure 6). Previously, HME methods relied on higher

483 temperatures amorphisation and mixing of the crystalline drug into the polymer

484 were commonly documented. However, the presence of a single distinctive glass

485 transition with the absence of melting endothermic event was observed for all

486 drug-EPO systems prepared by HME at predicted conditions (Figure 6, EXT

487 denoted for extruded samples). When comparing the thermograms of EXT

488 samples to the PM and QCPM, several clear differences can be summarised: 1) the

489 number of glass transitions, 2) the temperature of glass transitions and 3) the

490 melting event from the residual crystalline drug (Tablet 5-7).

491 In the case of IBU-EPO system, a homogeneous ASD can be achieved by both ball

492 milling and HME at drug loading below $0.6 \mathrm{w} / \mathrm{w}$, whilst, HME can further facilitate

493 the generation of one phase IBU ASD up to $0.65 \mathrm{w} / \mathrm{w}$ with EPO (Table 5). The high 
amorphisation capability of HME may be attributed to the fact that processing temperature is very close to the melting point of IBU. Additional shearing induced temperature elevation during HME can contribute to further dissolution of IBU 497 into EPO carrier (Censi et al., 2018; Liu et al., 2010). In addition, a higher $\mathrm{Tg}_{\mathrm{g}}$ 498 obtained from the EXT samples also indicates a more stable amorphous solid 499 dispersion system in comparison to the QCPMs.

500 In the case of NPX-EPO system, given the predicted NPX solubility in EPO was $5010.614 \mathrm{w} / \mathrm{w}$ at the processing temperature $\left(120^{\circ} \mathrm{C}\right.$, Table 4$)$, it was anticipated that 502 one-phase ASDs should be obtained for 0.45 and $0.60 \mathrm{w} / \mathrm{w}$ NPX-EPO system. This 503 was first validated by the thermal analysis, where a single $\mathrm{T}_{\mathrm{g}}$ with the absence of 504 melting event from NPX was recorded for NPX-EPO EXT samples (Table 6). Again 505 higher Tgs were recorded for all NPX-EPO EXT samples in comparison to the PM 506 or QCPM samples, where the presence of two $\mathrm{T}_{\mathrm{gS}}$ and/or melting event was 507 recorded. It was apparent that the use of HME enhanced the level of mixing 508 allowing for amorphisation of NPX-EPO at temperatures well below the melting of 509 crystalline NPX. Furthermore, for the PM sample containing $0.65 \mathrm{w} / \mathrm{w}$ NPX, there 510 was a broad melting endothermic peak observed before the crystalline NPX.

511 In the case of IND-EPO system, similar to the thermograms of NPX-EPO, both PM 512 and HME have converted the crystalline IND to amorphous at drug loading $<0.6$ $513 \mathrm{w} / \mathrm{w}$ (Table 7). In addition, two Tgs were observed for PM IND-EPO at $0.6 \mathrm{w} / \mathrm{w}$ 514 without the presence of melting events. It is clear that high drug loaded ASD can 515 be created well below the melting of the drug, with the use of F-H interaction 516 parameter as a guide, highlighting again the excellent miscibility of drug to 
polymer in the selected HDASDs. Furthermore, the $\mathrm{T}_{\mathrm{gS}}$ of all systems were also

518 significantly higher than the values predicted by the Gordon Taylor equation.

519 The implementation of HDASD systems in the design of HME process has enabled

520 the drug to dissolve in the polymeric carrier, reduced the viscosity of the system

521 and further enhanced amorphisation. The strength of the drug-polymer

522 interaction was further assessed using of the ATR-FTIR where the ASDs prepared

523 by HME and quench-cooled methods were compared. The IR absorption peaks

524 highlighting the carbonyl regions of the NSAIDs and amine regions of the EPO

525 were summarised in Table 8.

526 Based on the standard IR spectra for all the individual components, the 527 characteristic peak of the carbonyl group from EPO is normally observed at $5281728 \mathrm{~cm}^{-1}$, whilst, the carbonyl group for amorphous and crystalline IBU was 529 recorded at $1730 \mathrm{~cm}^{-1}$ and $1705 \mathrm{~cm}^{-1}$ respectively. These original IR absorption 530 peaks of IBU and EPO were used as the reference points as shown in Table 8. The 531 changes of these characteristic peaks after formation of ASD may indicate the level 532 of interactions within the system. An additional broadened peak was recorded at $5331576 \mathrm{~cm}^{-1}$ for extruded IBU-EPO samples at all drug loadings. This peak was 534 recorded to $1566 \mathrm{~cm}^{-1}$ in QCPM at $0.4 \mathrm{w} / \mathrm{w}$ IBU-EPO, but absent from higher drug 535 loadings. This peak was suggested to be the N-O stretching after the formation of 536 strong hydrogen-bonding (Moustafine et al., 2006). The broadening of the 537 spectrum is more prevalent in the extruded samples, highlighting the formation 538 of a strong hydrogen-bonding interaction during the production (Abu Ali et al., 539 2016). Carbonyl peak shifts were observed at the positions of 1709 to $1719 \mathrm{~cm}^{-1}$ 540 for IBU after extruded with EPO. These peak shifts represent the breaking of 
541 carbonyl $(\mathrm{C}=0)$ dimer structure in the original crystalline IBU. Interestingly, a 542 strong absorption peak at this position was observed in all extruded IBU-EPO 543 sample in comparison to the ASDS prepared by quench-cooled method. 544 Additionally, peak at $1716 \mathrm{~cm}^{-1}$ in $0.7 \mathrm{w} / \mathrm{w}$ IBU-EPO QCPM samples also suggests 545 the presence of crystalline IBU.

546 Similar to the IBU-EPO case, a stronger drug-polymer interaction between IND 547 and EPO was also suggested in the extruded ASDs in comparison to the quench548 cooled method (Figure 9). Peaks of relevance for crystalline IND were the 549 carbonyl group at $1713 \mathrm{~cm}^{-1}$ and $1690 \mathrm{~cm}^{-1}$, whilst, three peaks at 1735,1710 and $5501684 \mathrm{~cm}^{-1}$ were observed for amorphous IND. From the IR spectra, it can be 551 shown that the presence of the peak at $1682 \mathrm{~cm}^{-1}$, corresponding to the 552 amorphous IND (benzoyl $\mathrm{C}=0$ ) was evidenced in all ASD samples except in 0.7 553 w/w IND-EPO prepared by quench-cooled method.

554 The peak at $1690 \mathrm{~cm}^{-1}$ for $0.7 \mathrm{w} / \mathrm{w}$ quench-cooled IND-EPO indicated the presence 555 of crystalline IND. Additionally, the presence of the amorphous IND peak (1735 $556 \mathrm{~cm}^{-1}$ ) for both extruded samples and the $0.4 \mathrm{w} / \mathrm{w}$ quench-cooled IND-EPO ASD 557 suggests the amorphous nature of IND (Liu et al., 2012). The absence of the dimer 558 formation $\left(1710 \mathrm{~cm}^{-1}\right)$ for carbonyl peak at $1710^{-1} \mathrm{~cm}$ also suggests the formation 559 of stronger intermolecular interactions between IND and EPO in the extruded 560 HDASDs (Liu et al., 2012). Similar disruption of the dimer formation at the 561 carbonyl peak of the drug has also been discussed for hydrogen-bonding based 562 ASD systems (Taylor and Zografi, 1997).

563 The spectra of NPX with EPO (Figure 10) showed different characteristic peaks to 564 the other NSAID systems, with less focus on the carbonyl regions. In comparison 
565 of all the ASDs with crystalline NPX, an additional band at $1682 \mathrm{~cm}^{-1}$ relating to

566 the carboxylic acid dimer was only recorded for $0.65 \mathrm{w} / \mathrm{w}$ NPX-EPO system

567 prepared by quench-cooled method. The appearance of this peak indicated the

568 lack of drug-polymer interactions between EPO and NPX (Adibkia et al., 2013;

569 Doreth et al., 2016). An additional peak was recorded between 1200-1230 $\mathrm{cm}^{-1}$

570 for all the rest samples suggesting the formation of strong drug-polymer

571 interaction (Figure 10b). The effects of strong drug-EPO intermolecular

572 interactions for all three system facilitated by HME were further examined by in

573 vitro drug release studies. The rate and extend of drug release were significantly

574 higher for EXT samples in comparison to the QCPM samples (support information

575 Figure S3).

576

$577 \quad 3.5$ Verification of residual crystal in extrudates

578 Atomic force microscopy (AFM) was further used for to determine residual crystal

579 after extrusion. Through the use of phase contrast mode, outlining the phase

580 differences based on the adhesion and friction on the surface of the extrudates,

581 nanoscale and microscale domains may be differentiated. Examples of AFM phase

582 images $(10 \times 10 \mu \mathrm{m})$ of the NPX-EPO HDASD at three drug loadings $(0.45,0.6,0.7$

$583 \mathrm{w} / \mathrm{w}$ ) were presented in Figure $11(\mathrm{~d}-\mathrm{f})$ with corresponding 3D map of the surface

584 (a-c). The root mean square surface roughness of the extrudates were also

585 calculated based on the average of randomly selected five different samples. When

586 the initial drug loading was close to/exceeding the predicted liquid-solid curve

587 (Figure 6), an increase on the surface roughness was observed for both NPX-EPO

588 and IND-EPO HDASD systems. However, it was very difficult to characterise the

589 IBU-EPO HDASD systems using AFM due to the stick and rubbery nature of these 
samples at room temperature. Nevertheless, a smooth, homogenous surface (low

591 surface roughness, Figure $11 \mathrm{~g}$ ) with the absence of structured particles were

592 normally observed for NPX-EPO HDASD at drug loadings of $0.45 \mathrm{w} / \mathrm{w}(\mathrm{d})$ and 0.6

$593 \mathrm{w} / \mathrm{w}(\mathrm{e})$. In comparison, when drug loading was increased to $0.65 \mathrm{w} / \mathrm{w}$ (predicted

594 to be crystalline in NPX-EPO system), a sudden increase on surface roughness with

595 the appearance of structured particles can be observed by the AFM (Figure $11 \mathrm{c}, \mathrm{f}$

596 and g). With the calculated root mean square surface roughness for each extruded

597 systems, it was possible to direct visualise the transitions of the system from one-

598 phase amorphous to extrudates with residual crystals (Lauer et al., 2018).

\section{3.6 Storage of HDASDs at high humidity conditions}

600 Due to the ingression of water in the system at high humidity, microRaman 601 spectroscopic analysis was employed to monitor the appearance of crystalline 602 drug during storage. This technique has also been widely recommended to offer 603 the sensitivity of differentiating the crystalline and amorphous nature of the drug 604 within ASDs without the influence of moisture (Esmonde-White et al., 2017). It 605 was also suggested that the stability of these HDASDs system may be further 606 enhanced by the potential moisture-induced ionic interactions between weak 607 acidic drugs and polymer EPO (Sarode et al., 2013). In this work, the storage 608 conditions ( $\sim 95 \% \mathrm{RH})$ were achieved by preparing a saturated salt solution of 609 potassium nitrate at $20^{\circ} \mathrm{C}$. High humidity and high drug loading $(0.6 \mathrm{w} / \mathrm{w})$ were 610 used to accelerate the potential phase separation and crystallisation of drug from 611 the HDASDs (Figure 12). The correlation maps were constructed based on the 612 relative spectra correlation calculation between the freshly prepared HDASDs and 613 the spectra of crystalline drugs (white to black rainbow colour chart was used to 
614 represent the correlation ratio of $0.999-0.599)$. In the case of NPX, as observed

615 in the spectra shown in Figure 12a, the key peak of interest in the NPX spectrum 616 is at $3070 \mathrm{~cm}^{-1}$. This peak was observed in crystalline NPX but absent in the 617 amorphous from attributing to the aromatic $\mathrm{CH}$ stretching. At $0.6 \mathrm{w} / \mathrm{w}$ NPX drug 618 loading, the sample was shown to be amorphous both prior to and after three 619 weeks of high humidity storage with potential aggregation and amorphous phase 620 separation ( $\mathrm{T}=3$ weeks, chemical map). Similarly, IND also showed no 621 recrystallisation after 3 weeks of storage at the same high humidity conditions 622 (Figure 12b) indicating by the carbonyl peak at $1680 \mathrm{~cm}^{-1}$ in comparison to the $6231700 \mathrm{~cm}^{-1}$ from crystalline IND. This characteristic peak of amorphous IND was 624 recorded for $0.6 \mathrm{w} / \mathrm{w}$ IND-EPO HDASD prior to and after three weeks of storage. 625 Finally, in the case of $0.6 \mathrm{w} / \mathrm{w}$ IBU-EPO system where the characteristic peak at $6261608 \mathrm{~cm}^{-1}$ in the crystalline IBU and $1613 \mathrm{~cm}^{-1}$ in the HDASD was also clearly 627 observed (Rossi et al., 2009). Again, there was no apparent recrystallisation of the 628 drug after three weeks at high humidity storage (Figure 12c), however, a shift on 629 the correlation between amorphous and crystalline IBU was recorded with 630 potential drug aggregation after the storage.

\section{Conclusion}

632 Flory-Huggins based thermodynamic modelling is an informative framework for

633 the establishment of a design space of amorphous solid dispersion. Through the 634 constructed phase diagrams for all three HDASD systems, LCST behaviours were 635 obtained indicating the possibility of forming stable amorphous systems at high 636 drug loadings and low temperatures. Further characterisations on the extrudates 637 confirmed that the amorphisation of NPX, IBU and IND at these pre-defined 
638 conditions can be achieved by one-step continuous HME process. The 639 establishment of predictive thermodynamic model allows the interpretation and 640 evaluation of HME process in a well-defined space, in return, ensure the quality of 641 amorphous solid dispersions. Further work will be focused on the investigations 642 of kinetic impacts of the HME process based on the pre-defined thermodynamics 643 of the HDASD systems.

644

\section{References}

646 Abu Ali, H., Omar, S.N., Darawsheh, M.D., Fares, H., 2016. Synthesis, characterization and antimicrobial activity of zinc(II) ibuprofen complexes with nitrogen-based ligands. J. Coord. Chem. 69, 1110-1122. https://doi.org/10.1080/00958972.2016.1149819

Adibkia, K., Barzegar-Jalali, M., Maheri-Esfanjani, H., Ghanbarzadeh, S., Shokri, J., Sabzevari, A., Javadzadeh, Y., 2013. Physicochemical characterization of naproxen solid dispersions prepared via spray drying technology. Powder Technol. 246, 448-455. https://doi.org/10.1016/j.powtec.2013.05.044

654 Alshahrani, S.M., Lu, W., Park, J.B., Morott, J.T., Alsulays, B.B., Majumdar, S., Langley, N., Kolter, K., Gryczke, A., Repka, M.A., 2015. Stability-enhanced Hot-melt Extruded Amorphous Solid Dispersions via Combinations of Soluplus® and HPMCAS-HF. AAPS PharmSciTech 16, 824-834. 
Araujo, G.L.B. De, Benmore, C.J., Byrn, S.R., 2017. Local Structure of Ion Pair Interaction in Lapatinib Amorphous Dispersions characterized by Synchrotron X-Ray diffraction and Pair Distribution Function Analysis. Nat. Publ. Gr. 1-10. https://doi.org/10.1038/srep46367

Badman, C., Trout, B.L., 2014. Achieving Continuous Manufacturing. Int. Symp. Contin. Manuf. Pharm. 104, Intro White Paper. https://doi.org/10.1002/jps.24246

Baird, J. a., Taylor, L.S., 2012. Evaluation of amorphous solid dispersion properties using thermal analysis techniques. Adv. Drug Deliv. Rev. 64, 396421. https://doi.org/10.1016/j.addr.2011.07.009

Baird, J.A., Van Eerdenbrugh, B., Taylor, L.S., 2010. A Classification System to Assess the Crystallization Tendency of Organic Molecules from Undercooled Melts. J. Pharm. Sci. 99, 3787-3806. https://doi.org/10.1002/jps.22197

Caron, V., Tajber, L., Corrigan, O.I., Healy, A.M., 2011. A Comparison of Spray Drying and Milling in the Production of Amorphous Dispersions of Sulfathiazole/Polyvinylpyrrolidone and Sulfadimidine/Polyvinylpyrrolidone. Mol. Pharm. 8, 532-542. https://doi.org/10.1021/mp1003674

Censi, R., Gigliobianco, M.R., Casadidio, C., Di Martino, P., 2018. Hot Melt Extrusion: Highlighting Physicochemical Factors to Be Investigated While Designing and Optimizing a Hot Melt Extrusion Process. Pharmaceutics 10. https://doi.org/10.3390/pharmaceutics10030089

Dadou, S.M., Senta-Loys, Z., Almajaan, A., Li, S., Jones, D.S., Healy, A.M., Tian, Y., Andrews, G.P., 2020. The development and validation of a quality by design 
based process analytical tool for the inline quantification of Ramipril during hot-melt extrusion. Int. J. Pharm. 584. https://doi.org/10.1016/j.ijpharm.2020.119382

Dave, H., Gao, F., Lee, J.H., Liberatore, M., Ho, C.C., Co, C.C., 2007. Self-assembly in sugar-oil complex glasses. Nat. Mater. 6, 287-290. https://doi.org/10.1038/nmat1864

Dedroog, S., Huygens, C., Van den Mooter, G., 2019. Chemically identical but physically different: A comparison of spray drying, hot melt extrusion and cryo-milling for the formulation of high drug loaded amorphous solid dispersions of naproxen. Eur. J. Pharm. Biopharm. 135, 1-12. https://doi.org/10.1016/j.ejpb.2018.12.002

DiNunzio, J.C., Hughey, J.R., Brough, C., Miller, D. a, Williams, R.O., McGinity, J.W., 2010. Production of advanced solid dispersions for enhanced bioavailability of itraconazole using KinetiSol Dispersing. Drug Dev. Ind. Pharm. 36, 106478. https://doi.org/10.3109/03639041003652973

Donnelly, C., Tian, Y., Potter, C.C.C., Jones, D.S.D.S., Andrews, G.P.G.P., 2014. Probing the Effects of Experimental Conditions on the Character of DrugPolymer Phase Diagrams Constructed Using Flory-Huggins Theory. Pharm. Res. 32, 167-179. https://doi.org/10.1007/s11095-014-1453-9

Doreth, M., L?bmann, K., Grohganz, H., Holm, R., Lopez de Diego, H., Rades, T., Priemel, P.A., 2016. Glass solution formation in water - In situ amorphization of naproxen and ibuprofen with Eudragit? E PO. J. Drug Deliv. Sci. Technol. 34, 32-40. https://doi.org/10.1016/j.jddst.2016.02.003 
712 Emel'yanenko, V.N., Verevkin, S.P., Heintz, A., 2007. The Gaseous Enthalpy of Formation of the Ionic Liquid 1-Butyl-3-methylimidazolium Dicyanamide from Combustion Calorimetry, Vapor Pressure Measurements, and Ab Initio

717 Esmonde-White, K.A., Cuellar, M., Uerpmann, C., Lenain, B., Lewis, I.R., 2017.

FDA, 2012. Approval letter for Kalydeco. Approv. Lett. 1-5.

FDA, 2015. Orkambi Prescribing information 1-16.

FDA, 2019b. FDA approves new breakthrough therapy for cystic fibrosis [WWW Document]. URL https://www.fda.gov/news-events/pressannouncements/fda-approves-new-breakthrough-therapy-cystic-fibrosis thermodynamic and kinetic parameters with amorphous stability. Eur. J. 
734

735

736

737

738

739

740

741

742

743

744

745

746

747

748

749

750

751

752

753

754

755

Hancock, B.C.C., Zografi, G., 1997. Characteristics and significance of the amorphous state in pharmaceutical systems. J. Pharm. Sci. 86, 1-12. https://doi.org/10.1021/js9601896

Huang, S., O’Donnell, K.P., Delpon de Vaux, S.M., O’Brien, J., Stutzman, J., Williams, R.0., 2017. Processing thermally labile drugs by hot-melt extrusion: The lesson with gliclazide. Eur. J. Pharm. Biopharm. 119, 56-67. https://doi.org/10.1016/j.ejpb.2017.05.014

Huang, S., O’Donnell, K.P., Keen, J.M., Rickard, M.A., McGinity, J.W., Williams, R.O., 2016. A New Extrudable Form of Hypromellose: AFFINISOLTM HPMC HME. AAPS PharmSciTech 17, 106-119. https://doi.org/10.1208/s12249-0150395-9

Jones, D., 2004. Pharmaceutical Applications of Polymers for Drug Delivery, Polysaccharides for Drug Delivery and Pharmaceutical Applications.

Kalepu, S., Nekkanti, V., 2015. Insoluble drug delivery strategies: Review of recent advances and business prospects. Acta Pharm. Sin. B. https://doi.org/10.1016/j.apsb.2015.07.003

Kapnistos, M., Hinrichs, A., Vlassopoulos, D., Anastasiadis, S.H., Stammer, A., Wolf, B.A., 1996. Rheology of a Lower Critical Solution Temperature Binary Polymer Blend in the Homogeneous, Phase-Separated, and Transitional Regimes. Macromolecules1 29, 7155-7163. https://doi.org/10.1021/ma960835n

Keen, J.M., Martin, C., MacHado, A., Sandhu, H., McGinity, J.W., Dinunzio, J.C., 2014. 
Investigation of process temperature and screw speed on properties of a pharmaceutical solid dispersion using corotating and counter-rotating twinscrew extruders. J. Pharm. Pharmacol. 66, 204-217. https://doi.org/10.1111/jphp.12106

760

761

762

763

764

765

766

767

768

769

770

771

772

773

774

775

776

777

778

Knopp, M.M.M.M., Tajber, L., Tian, Y., Olesen, N.E., Jones, D.S.D.S., Kozyra, A., Löbmann, K., Paluch, K., Brennan, C.M.C.M., Holm, R., Healy, A.M.A.M., Andrews, G.P.G., Rades, T., Loebmann, K., Paluch, K., Brennan, C.M.C.M., Holm, R., Healy, A.M.A.M., Andrews, G.P.G., Rades, T., 2015. Comparative study of different methods for the prediction of drug-polymer solubility. Mol. Pharm. 12, 3408-3419. https://doi.org/10.1021/acs.molpharmaceut.5b00423

Lauer, M.E., Maurer, R., Paepe, A.T. De, Stillhart, C., Jacob, L., James, R., Kojima, Y., Rietmann, R., Kissling, T., van den Ende, J.A., Schwarz, S., Grassmann, O., Page, S., 2018. A Miniaturized Extruder to Prototype Amorphous Solid Dispersions: Selection of Plasticizers for Hot Melt Extrusion. Pharmaceutics 10, 58. https://doi.org/10.3390/pharmaceutics10020058

Lin, D., Huang, Y., 2010. A thermal analysis method to predict the complete phase diagram of drug-polymer solid dispersions. Int. J. Pharm. 399, 109-115. https://doi.org/10.1016/j.ijpharm.2010.08.013

Liu, H., Wang, P., Zhang, X., Shen, F., Gogos, C.G., 2010. Effects of extrusion process parameters on the dissolution behavior of indomethacin in Eudragit® E PO solid dispersions. Int. J. Pharm. 383, 161-169. https://doi.org/10.1016/j.ijpharm.2009.09.003

779 Liu, H., Zhang, X., Suwardie, H., Wang, P., Gogos, C.G., 2012. Miscibility studies of 
indomethacin and Eudragit $®$ E PO by thermal, rheological, and spectroscopic analysis. J. Pharm. Sci. 101, 2204-2212. https://doi.org/10.1002/jps.23075

783

784

785

786

787

788

789

790

791

792

793

794

795

796

797

798

799

800

801

802

Luebbert, C., Huxoll, F., Sadowski, G., Van Den Mooter, G., Grohganz, H., 2017. Amorphous-amorphous phase separation in API/polymer formulations. Molecules 22, 1-17. https://doi.org/10.3390/molecules22020296

Luebbert, C., Klanke, C., Sadowski, G., 2018. Investigating phase separation in amorphous solid dispersions via Raman mapping. Int. J. Pharm. 535, 245252. https://doi.org/10.1016/j.ijpharm.2017.11.014

Mahlin, D., Bergström, C.A.S., 2013. Early drug development predictions of glassforming ability and physical stability of drugs. Eur. J. Pharm. Sci. 49, 323332. https://doi.org/10.1016/j.ejps.2013.03.016

Marsac, P.J., Li, T., Taylor, L.S., 2009. Estimation of drug-polymer miscibility and solubility in amorphous solid dispersions using experimentally determined interaction parameters. Pharm. Res. 26, 139-151. https://doi.org/10.1007/s11095-008-9721-1

Marsac, P.J., Shamblin, S.L., Taylor, L.S., 2006. Theoretical and practical approaches for prediction of drug-polymer miscibility and solubility. Pharm. Res. 23, 2417-2426. https://doi.org/10.1007/s11095-006-9063-9

Meredith, J.C., Amis, E.J., 2000. LCST phase separation in biodegradable polymer blends: poly(D,L-lactide) and poly(epsilon-caprolactone). Macromol. Chem. Phys. 201, 733-739. https://doi.org/10.1002/(sici)15213935(20000301)201:6<733::aid-macp733>3.3.co;2-x 
803

804

805

806

807

808

809

810

811

812

813

814

815

816

817

818

819

820

821

822

823

824

825

826

Mistry, P., Mohapatra, S., Gopinath, T., Vogt, F.G., Suryanarayanan, R., 2015. Role of the Strength of Drug-Polymer Interactions on the Molecular Mobility and Crystallization Inhibition in Ketoconazole Solid Dispersions. Mol. Pharm. 12, 3339-3350. https://doi.org/10.1021/acs.molpharmaceut.5b00333

Mori, T., Beppu, S., Berber, M.R., Mori, H., Makimura, T., Tsukamoto, A., Minagawa, K., Hirano, Tomohiro, Tanaka, M., Niidome, T., Katayama, Y., Hirano, Tatsuya, Maeda, Y., 2010. Design of temperature-responsive polymers with enhanced hysteresis: $\alpha, \alpha$-disubstituted vinyl polymers. Langmuir 26, 9224-9232. https://doi.org/10.1021/la100020t

Moustafine, R.I., Zaharov, I.M., Kemenova, V.A., 2006. Physicochemical characterization and drug release properties of Eudragit ${ }^{\circledR}$ E PO/Eudragit $®$ L 100-55 interpolyelectrolyte complexes. Eur. J. Pharm. Biopharm. 63, 2636. https://doi.org/10.1016/j.ejpb.2005.10.005

Pajula, K., Taskinen, M., Lehto, V.-P.P., Ketolainen, J., Korhonen, O., 2010. Predicting the Formation and Stability of Amorphous Small Molecule Binary Mixtures from Computationally Determined Flory-Huggins Interaction Parameter and Phase Diagram. Mol. Pharm. 7, 795-804. https://doi.org/10.1021/mp900304p

Paudel, A., Nies, E., Van Den Mooter, G., 2012. Relating hydrogen-bonding interactions with the phase behavior of naproxen/PVP K 25 solid dispersions: Evaluation of solution-cast and quench-cooled films. Mol. Pharm. 9, 3301-3317. https://doi.org/10.1021/mp3003495

Purohit, H.S., Taylor, L.S., 2015. Miscibility of Itraconazole-Hydroxypropyl Methylcellulose Blends: Insights with High Resolution Analytical 
Quinteros, D.A., Rigo, V.R., Kairuz, A.F.J., Olivera, M.E., Manzo, R.H., Allemandi, D.A., 2008. Interaction between a cationic polymethacrylate (Eudragit E100) and anionic drugs. Eur. J. Pharm. Sci. 33, 72-79.

832 https://doi.org/10.1016/j.ejps.2007.10.002

833 834 835 836

Repka, M.A., Bandari, S., Kallakunta, V.R., Vo, A.Q., McFall, H., Pimparade, M.B., Bhagurkar, A.M., 2018. Melt extrusion with poorly soluble drugs - An integrated review. Int. J. Pharm. 535, 68-85. https://doi.org/10.1016/j.ijpharm.2017.10.056

Rossi, B., Verrocchio, P., Viliani, G., Mancini, I., Guella, G., Rigo, E., Scarduelli, G., Mariotto, G., 2009. Vibrational properties of ibuprofen-cyclodextrin inclusion complexes investigated by Raman scattering and numerical simulation. J. Raman Spectrosc. 40, 453-458. https://doi.org/10.1002/jrs.2150

Rubinstein, M., Colby, R.H., 2003. Polymer physics, Polymer International. Oxford University Press. https://doi.org/10.1002/pi.1472

Sarode, A.L., Sandhu, H., Shah, N., Malick, W., Zia, H., 2013. Hot Melt Extrusion for Amorphous Solid Dispersions : Temperature and Moisture Activated Drug Polymer Interactions for Enhanced Stability.

Schammé, B., Couvrat, N., Tognetti, V., Delbreilh, L., Dupray, V., Dargent, É., Coquerel, G., 2018. Investigation of Drug-Excipient Interactions in Biclotymol Amorphous Solid Dispersions. Mol. Pharm. acs.molpharmaceut.7b00993. 
852

Song, Y., Yang, X., Chen, X., Nie, H., Byrn, S., Lubach, J.W., 2015. Investigation of Drug-Excipient Interactions in Lapatinib Amorphous Solid Dispersions Using Solid-State NMR Spectroscopy. Mol. Pharm. 12, 857-866. https://doi.org/10.1021/mp500692a

Sylvie, Tencé-Girault, Sylvie, L., Oana, B., Patrick, D., François, B., 2019. Crystals, Vol. 9, Pages 271: Simultaneous SAXS-WAXS Experiments on SemiCrystalline Polymers: Example of PA11 and Its Brill Transition. Crystals 9, 271. https://doi.org/10.3390/cryst9050271

Tanaka, H., Nishi, T., 1989. Local phase separation at the growth front of a polymer spherulite during crystallization and nonlinear spherulitic growth in a polymer mixture with a phase diagram. Phys. Rev. A 39, 783-794. https://doi.org/10.1103/PhysRevA.39.783

Taylor, L.S., Zografi, G., 1997. Spectroscopic characterization of interactions between PVP and indomethacin in amorphous molecular dispersions. Pharm. Res. https://doi.org/10.1023/A:1012167410376

Tian, Y., Booth, J., Meehan, E., Jones, D.S.D.S., Li, S., Andrews, G.P.G.P., 2013. Construction of drug-polymer thermodynamic phase diagrams using floryhuggins interaction theory: Identifying the relevance of temperature and drug weight fraction to phase separation within solid dispersions. Mol. Pharm. 10, 236-248. https://doi.org/10.1021/mp300386v

Tian, Y., Caron, V., Jones, D.S.D.S., Healy, A.-M.A.M., Andrews, G.P.G.P., 2014. Using Flory-Huggins phase diagrams as a pre-formulation tool for the production of amorphous solid dispersions: A comparison between hot-melt extrusion 
875

876

877

878

879

880

881

882

883

884

885

886

887

888

889

890

891

892

893

894

895

896

897

898

and spray drying. J. Pharm. Pharmacol. 66, 256-274.

https://doi.org/10.1111/jphp.12141

Tian, Y., Jones, D.S.D.S., Andrews, G.P.G.P., 2015. An investigation into the role of polymeric carriers on crystal growth within amorphous solid dispersion systems. Mol. Pharm. 12, 150306122810000. https://doi.org/10.1021/mp500702s

Tian, Y., Jones, D.S.D.S., Donnelly, C., Brannigan, T., Li, S., Andrews, G.P.G.P., 2018. A New Method of Constructing a Drug-Polymer Temperature-Composition Phase Diagram Using Hot-Melt Extrusion. Mol. Pharm. 15, 1379-1391. https://doi.org/10.1021/acs.molpharmaceut.7b00445

Tian, Y., Qian, K., Jacobs, E., Amstad, E., Jones, D.S., Stella, L., Andrews, G.P., 2019. The Investigation of Flory - Huggins Interaction Parameters for Amorphous Solid Dispersion Across the Entire Temperature and Composition Range. Pharmaceutics 11, 420.

Ueda, H., Wakabayashi, S., Kikuchi, J., Ida, Y., Kadota, K., Tozuka, Y., 2015. Anomalous role change of tertiary amino and ester groups as hydrogen acceptors in eudragit $\mathrm{E}$ based solid dispersion depending on the concentration of naproxen. Mol. Pharm. 12, 1050-1061. https://doi.org/10.1021/mp5005417

Zhang, J., Han, R., Chen, W., Zhang, W., Li, Y., Ji, Y., Chen, L., Pan, H., Yang, X., Pan, W., Ouyang, D., 2018. Analysis of the Literature and Patents on Solid Dispersions from 1980 to 2015. Molecules 23, 1-19. https://doi.org/10.3390/molecules23071697

Zhao, Y., Inbar, P., Chokshi, P.H., Malick, A.W., Choi, D., 2010. Prediction of 

thermal phase diagram of amorphous solid dispersions by Flory-Huggins

901 Table 1 Physicochemical properties for drugs and polymer used in this study 902 (Cai et al., 2011; Kindermann et al., 2011; Li et al., 2016; Ng et al., 2013).

\begin{tabular}{|c|c|c|c|c|}
\hline Substance & $\mathrm{T}_{\mathrm{g}}\left({ }^{\circ} \mathrm{C}\right)$ & $\mathrm{T}_{\mathrm{m}}\left({ }^{\circ} \mathrm{C}\right)$ & $\begin{array}{c}\text { Molecular weight } \\
(\mathrm{g} / \mathrm{mol})\end{array}$ & $\begin{array}{c}\text { Density } \\
\left(\mathrm{g} / \mathrm{cm}^{3}\right)\end{array}$ \\
\hline Eudragit® E (EPO) & 48 & - & 47000.00 & 0.83 \\
\hline Naproxen & 6 & 152 & 230.59 & 1.29 \\
\hline Ibuprofen & -44 & 76 & 206.29 & 1.03 \\
\hline Indomethacin & 50 & 156 & 357.79 & 1.32 \\
\hline
\end{tabular}

903

904

905

906 907

908

909

910

911

912

913

Table 2 HME process conditions and drug loadings for EPO with drug IND, NPX and IBU

\begin{tabular}{|c|c|c|}
\hline Systems & $\begin{array}{c}\text { Process condition, full } \\
\text { convey }(11 \mathrm{~mm}, \mathrm{~L} / \mathrm{D} 20: 1)\end{array}$ & $\begin{array}{c}\text { Drug weight fractions } \\
(\mathrm{w} / \mathrm{w})\end{array}$ \\
\hline indomethacin - EPO & $\mathbf{1 2 0}^{\circ} \mathbf{C}, 60 \mathrm{RPM}$ & $\mathbf{0 . 4 ; ~ 0 . 6 ; ~ 0 . 7 ~}$ \\
\hline naproxen - EPO & $\mathbf{1 2 0}^{\circ} \mathbf{C}, 60 \mathrm{RPM}$ & $\mathbf{0 . 4 5 ; 0 . 6 ; 0 . 6 5}$ \\
\hline ibuprofen - EPO & $\mathbf{6 5}^{\circ} \mathbf{C}, 60 \mathrm{RPM}$ & $\mathbf{0 . 4 5 ; 0 . 6 ; 0 . 7}$ \\
\hline
\end{tabular}

Table 3 Flory-Huggins interaction parameter constants for system IND+EPO, $\mathrm{NPX}+\mathrm{EPO}$ and IBU+EPO

\begin{tabular}{|c|c|c|c|}
\hline HDASDs & $\mathrm{B}$ & $\mathrm{A}$ & $\mathrm{R}^{2}$ \\
\hline IND-EPO & -19601 & 42.39 & 0.93 \\
\hline NPX-EPO & -8072.5 & 17.28 & 0.94 \\
\hline IBU-EPO & -9083.2 & 24.86 & 0.97 \\
\hline
\end{tabular}


Table 4 The predicted drug-EPO solubility as function of temperatures for IND,

915 NPX and IBU systems

916

917

918

919

920

921

922

923

\begin{tabular}{|c|c|c|c|}
\hline Temperatures $\left({ }^{\circ} \mathrm{C}\right)$ & $\begin{array}{c}\text { IND solubility in } \\
\text { EPO }(\mathrm{w} / \mathrm{w})^{\S}\end{array}$ & $\begin{array}{c}\text { NPX solubility in } \\
\text { EPO }(w / w)\end{array}$ & $\begin{array}{c}\text { IBU solubility in } \\
\text { EPO }(w / w)\end{array}$ \\
\hline 20 & 0.631 & 0.473 & 0.541 \\
\hline 30 & 0.634 & 0.480 & 0.557 \\
\hline 50 & 0.641 & 0.495 & 0.611 \\
\hline 70 & 0.651 & 0.516 & 0.766 \\
\hline 90 & 0.664 & 0.544 & 1 \\
\hline 120 & 0.699 & 0.614 & Spinodal region \\
\hline
\end{tabular}

* data for drug solubility in polymer EPO was predicted through the constructed temperature-composition phase diagrams

$\S$ denoted the values are not statistically significant at different temperatures suggesting a less temperature dependent drug-polymer interaction parameters $(\mathrm{p}>0.05)$

Table 5 Thermal events recorded using DSC for IBU-EPO mixtures at selected drug loadings

\begin{tabular}{|c|c|c|}
\hline Sample & Glass Transition $\left({ }^{\circ} \mathrm{C}\right)$ & Melting Event $\left({ }^{\circ} \mathrm{C}\right)$ \\
\hline 0.45 IBU_PM & $7.41 \pm 0.32$ & - \\
\hline 0.45 IBU_EXT & $3.62 \pm 1.4$ & - \\
\hline 0.6 IBU_PM & $-15.97 \pm 1.6$ & $65.23-81.64$ \\
\hline 0.6 IBU_EXT & $4.67 \pm 1.1$ & - \\
\hline 0.65 IBU_PM & $-21.88 \pm 0.91$ & $58.78-84.57$ \\
\hline 0.65 IBU_EXT & $-13.6 \pm 0.81$ & - \\
\hline
\end{tabular}

* Glass transition temperatures were average value \pm standard deviation $(n=3)$

Table 6 Thermal events recorded using DSC for NPX-EPO mixtures at selected drug loadings and production methods

\begin{tabular}{|c|c|c|}
\hline Sample & Glass Transition $\left({ }^{\circ} \mathrm{C}\right)$ & Melting Event $\left({ }^{\circ} \mathrm{C}\right)$ \\
\hline 0.45 NPX_BM & $36.57 \pm 0.61$ & - \\
\hline 0.45 NPX_EXT & $38.1 \pm 0.69$ & - \\
\hline 0.6 NPX_BM & $35.58 \pm 0.93$ & - \\
\hline 0.6 NPX_EXT & $38.23 \pm 0.45$ & - \\
\hline 0.65 NPX_BM & $28.34 \pm 0.11$ & $133.14 \pm 1.50$ \\
\hline 0.65 NPX_EXT & $36.42 \pm 0.45$ & - \\
\hline
\end{tabular}


* Glass transition temperatures were average value \pm standard deviation ( $\mathrm{n}=3$ )

928

929

930

931

932

933

934

935

936

937

(a)<smiles>CCCCCC(C)(CC(C)(CC(C)(CC)C(=O)OC)C(=O)OC)C(=O)OC</smiles>
loading and production methods different production methods

Fig.1

Table 7 Thermal events measured using DSC of IND_EPO mixes at different drug

\begin{tabular}{|c|c|c|}
\hline Sample & Glass Transition $\left({ }^{\circ} \mathrm{C}\right)$ & Melting Event $\left({ }^{\circ} \mathrm{C}\right)$ \\
\hline 0.4 IND_BM & $53.50 \pm 0.36$ & - \\
\hline 0.4 IND_EXT & $54.70 \pm 0.46$ & - \\
\hline 0.6 IND PM & $31.10 \pm 1.4$ & $81.35-120.45$ \\
\hline 0.6 IND EXT & $59.49 \pm 0.67$ & - \\
\hline 0.7 IND PM & 19.24 & $82.2-132.67$ \\
\hline 0.7 IND EXT & $54.27 \pm 0.77$ & $126.21-147.58$ \\
\hline
\end{tabular}

* Glass transition temperatures were average value \pm standard deviation $(n=3)$

Table 8 The key IR absorption peaks for all drug-polymer ASDs prepared via

\begin{tabular}{|c|c|c|c|c|c|c|}
\hline \multirow{2}{*}{$\begin{array}{c}\text { Tested } \\
\text { samples }\end{array}$} & \multicolumn{5}{|c|}{ Key peaks presented by IR wavenumbers (cm-1) } \\
\cline { 2 - 7 } & \multicolumn{2}{|c|}{ IND_EPO } & \multicolumn{2}{c|}{ NPX_EPO } & \multicolumn{2}{c|}{ IBU_EPO } \\
\cline { 2 - 7 } & HME & QCPM & HME & QCPM & HME & QCPM \\
\hline $\begin{array}{c}\text { Higher drug } \\
\text { loadings } \\
(0.65 / 0.7)\end{array}$ & 1682 & 1690 & - & 1682 & 1576 & - \\
\hline $\begin{array}{c}\text { Lower drug } \\
\text { loadings } \\
(0.45 / 0.4)\end{array}$ & 1735 & - & - & 1176 & 1729 & 1716 \\
\hline
\end{tabular}

938
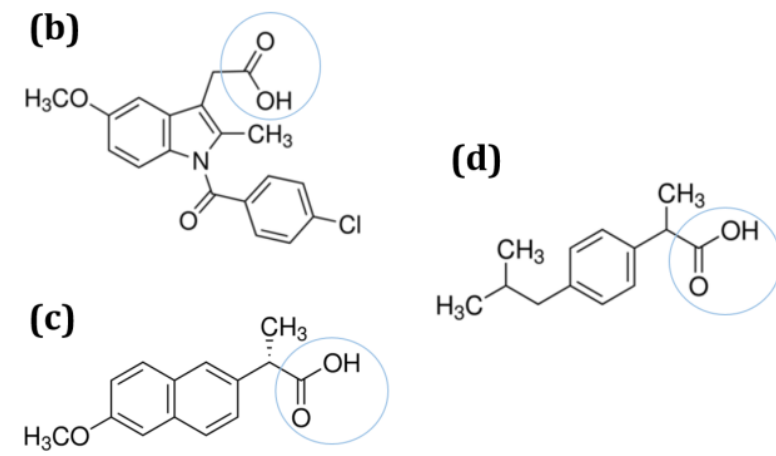
Fig. 2


940
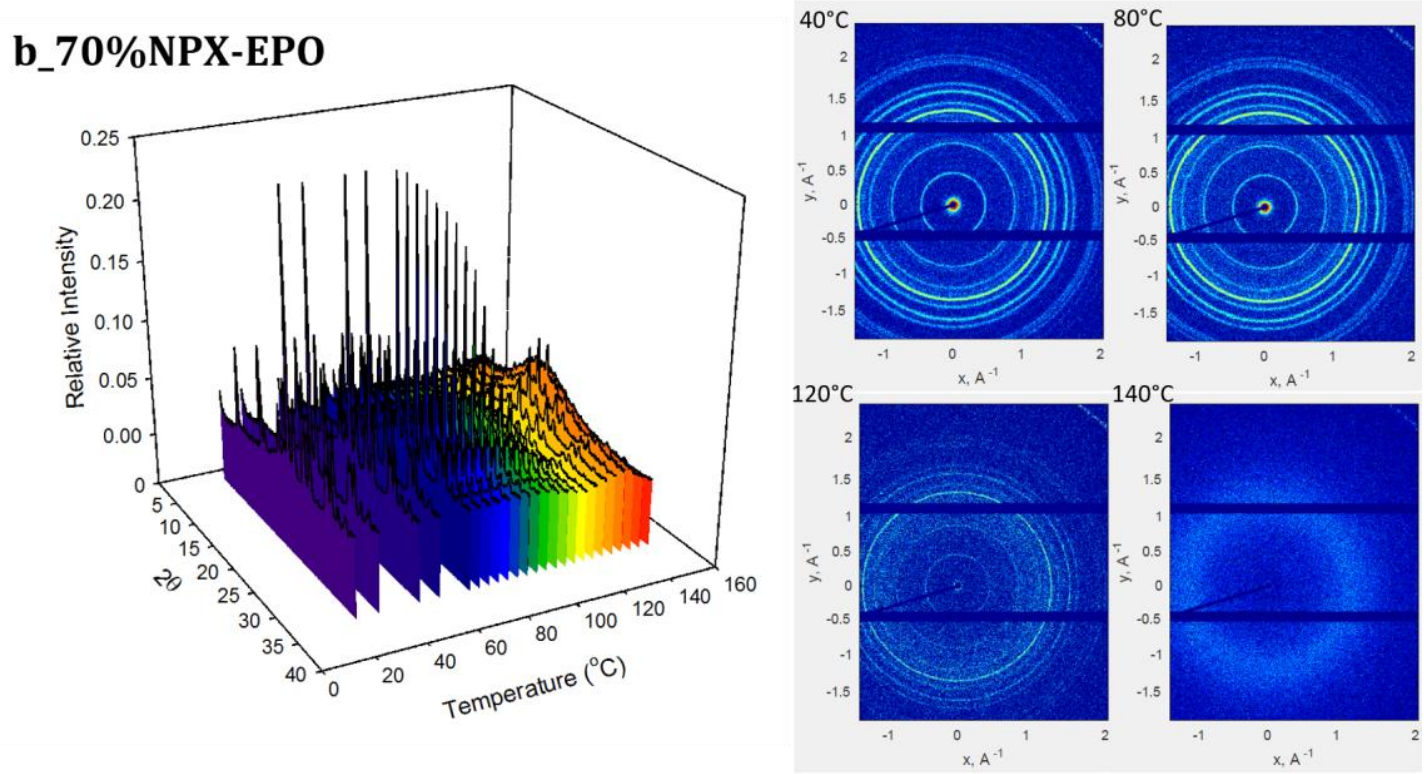



942

$943 \quad$ Fig. 3

50\%IBU-EPO, ball-milled 10 mins, $15 \mathrm{~Hz}$



WAXS, 60 seconds, vacuum

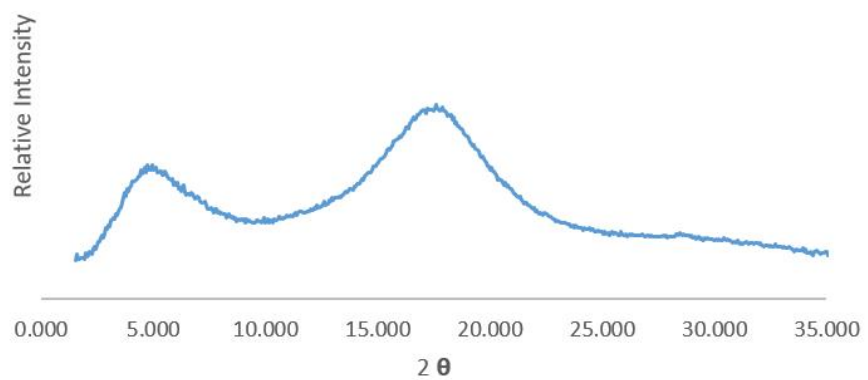

latest_0002142_caz (log intensity scale)

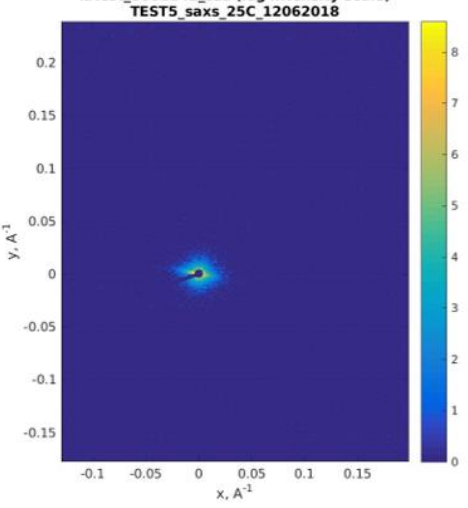

SAXS, 600 seconds, vacuum

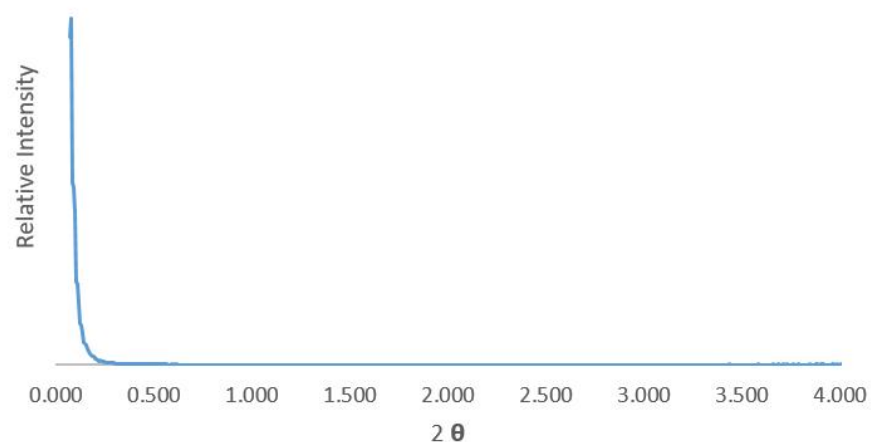


Fig. 4

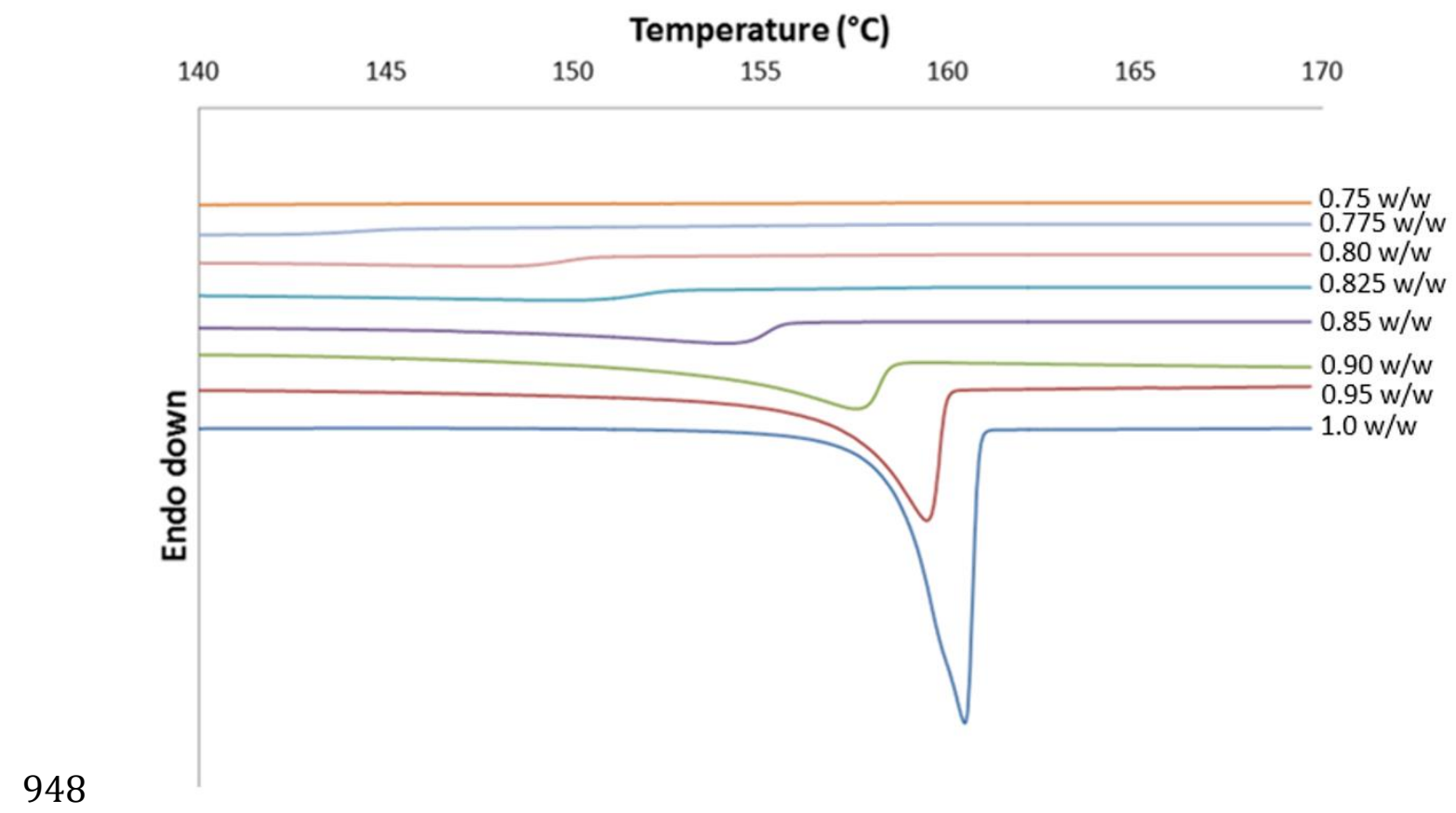

$949 \quad$ Fig.5

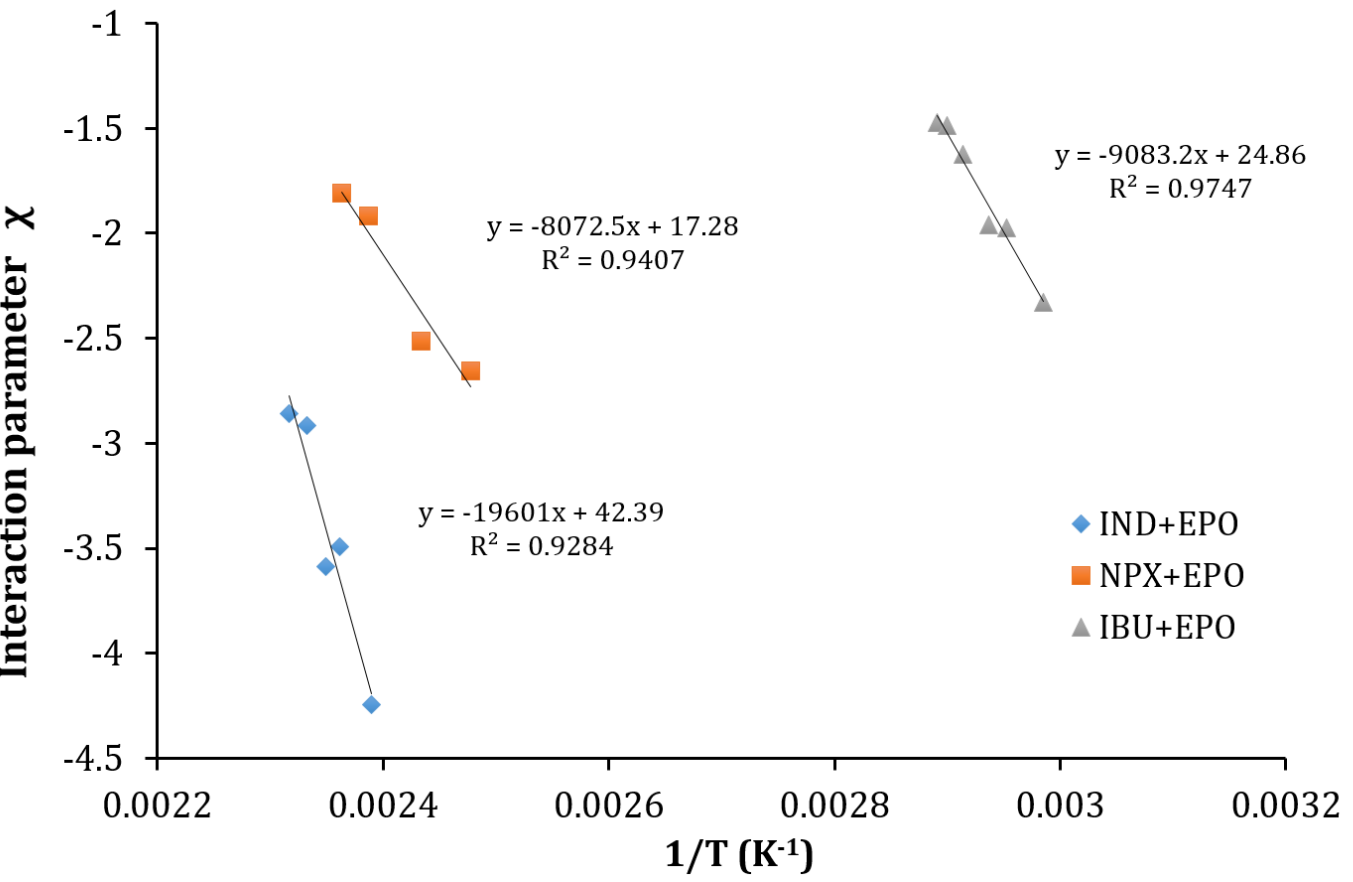

951

952 


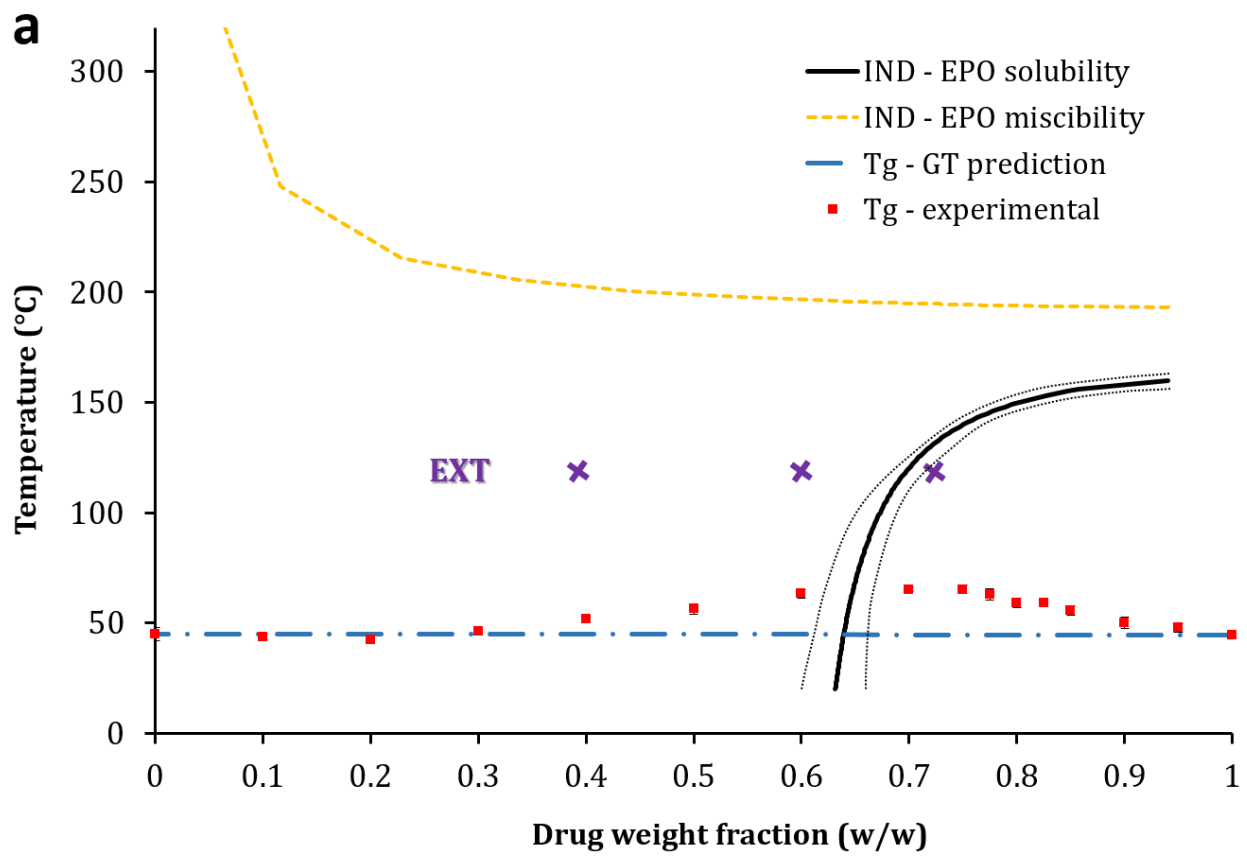

954

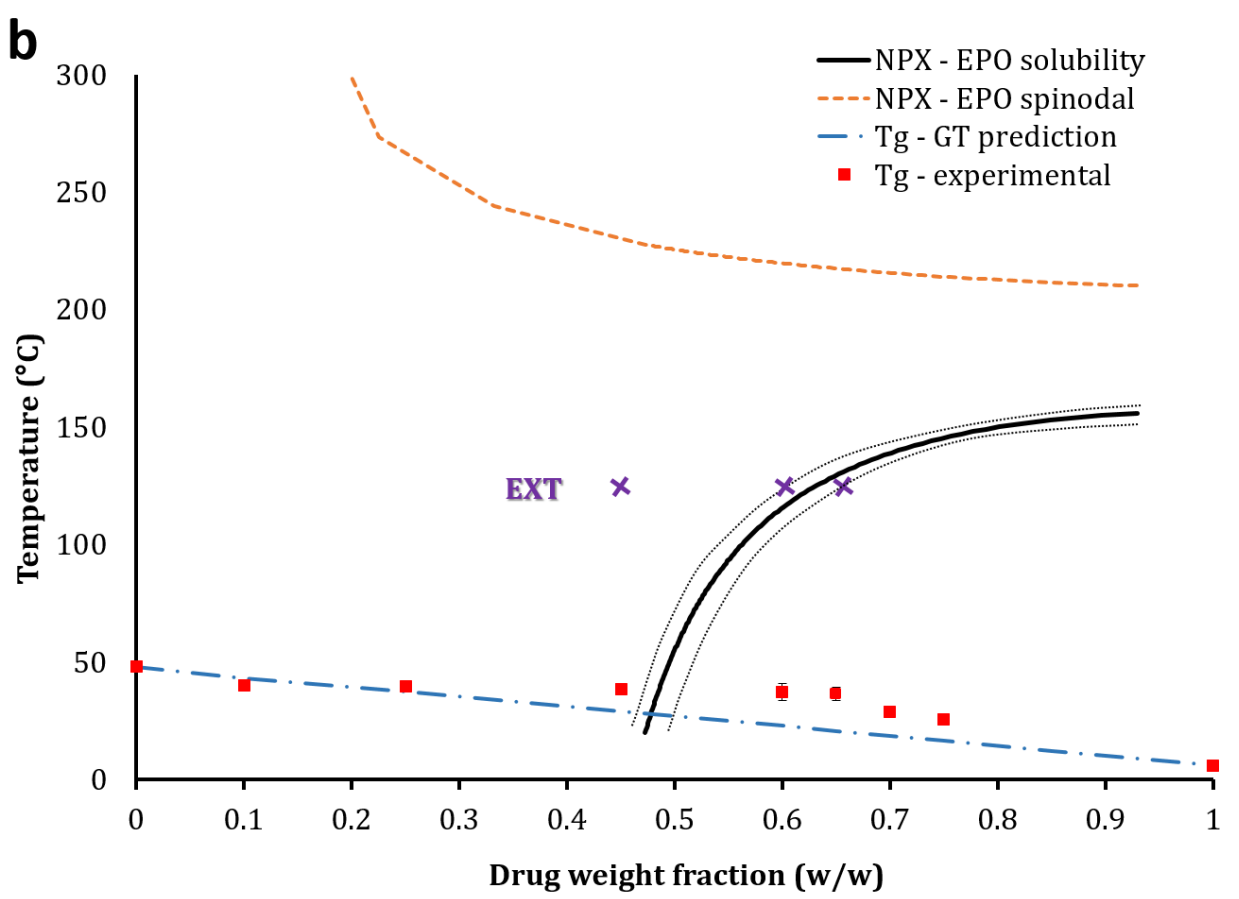

955 


\section{C}

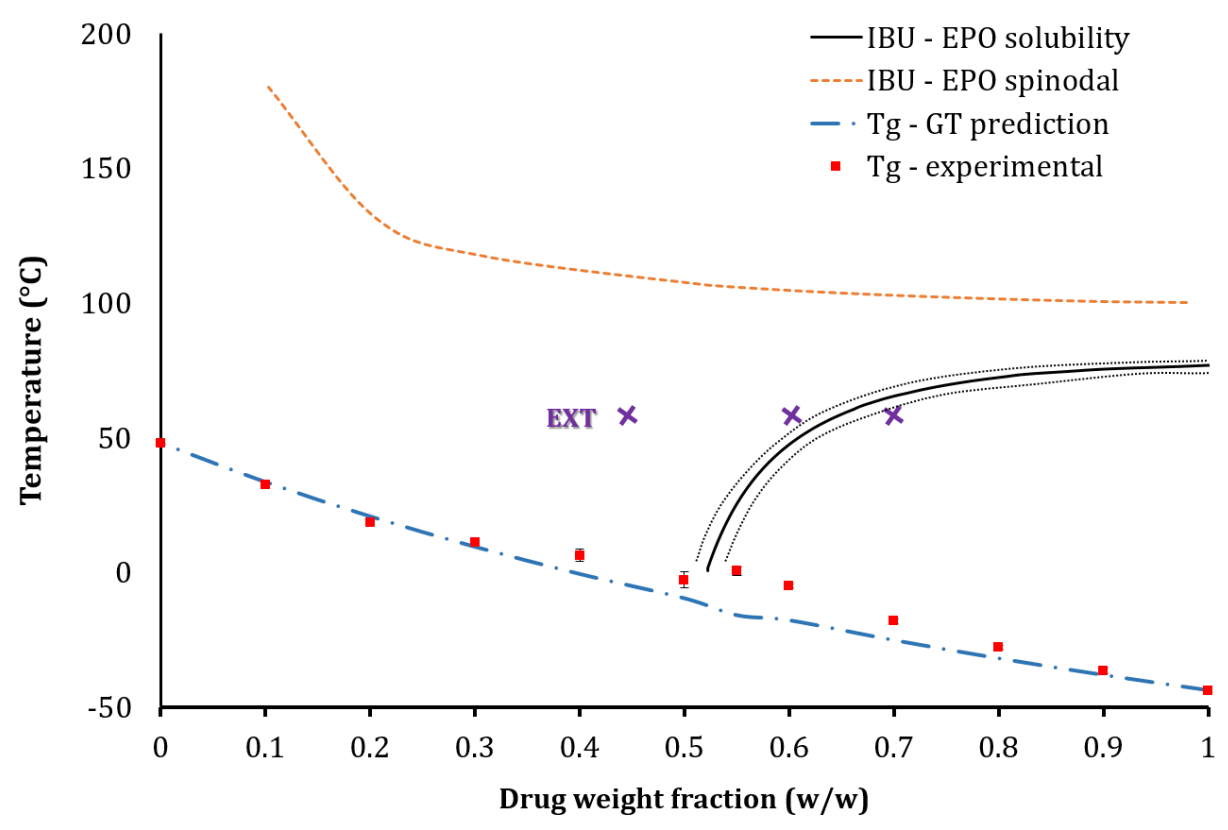

958

$959 \quad$ Fig.7



960

Drug weight fraction (w/w) 


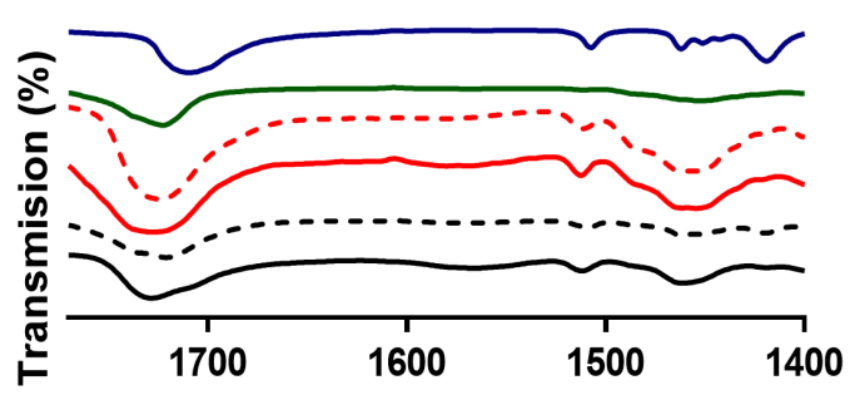

- IBU

- EPO

- - 0.45 w/w IBU QCPM

- $0.45 \mathrm{w} / \mathrm{w}$ IBU EXT

-- 0.7 w/w IBU QCPM

- $0.7 \mathrm{w} / \mathrm{w}$ IBU EXT

\section{Wavenumber $\mathrm{cm}^{-1}$}

963

$964 \quad$ Fig.9

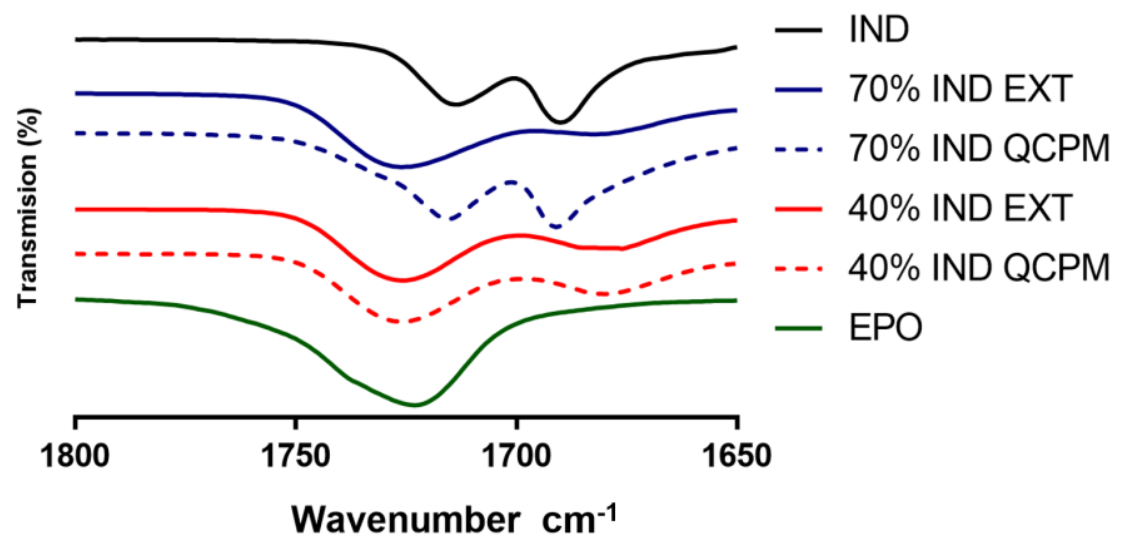

$966 \quad$ Fig.10

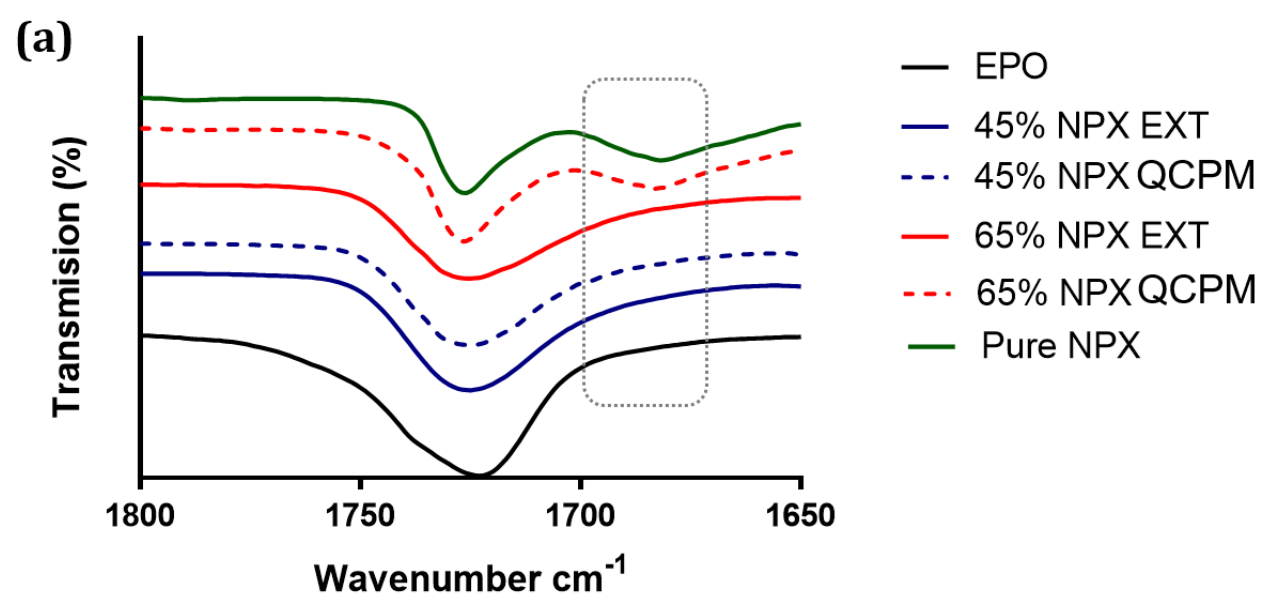






968

$969 \quad$ Fig.11

Examples of NPX-EPO EXTs

$0.45 \mathrm{w} / \mathrm{w} \quad 0.60 \mathrm{w} / \mathrm{w} \quad 0.65 \mathrm{w} / \mathrm{w}$



(d)

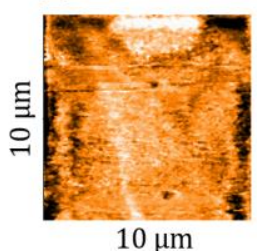

(e)

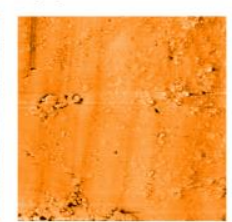

(f)

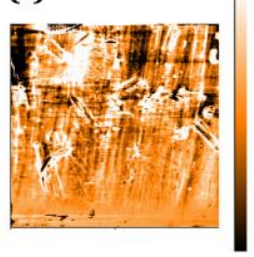



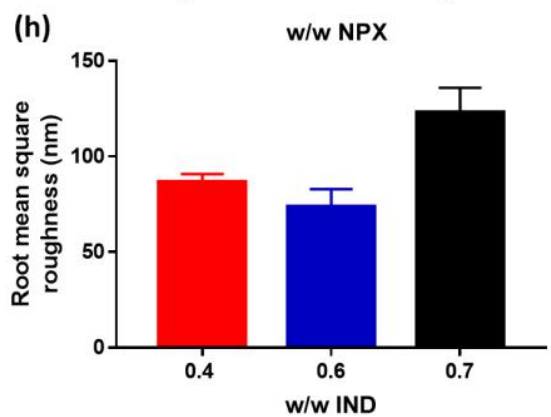

970

971 
Fig. 12
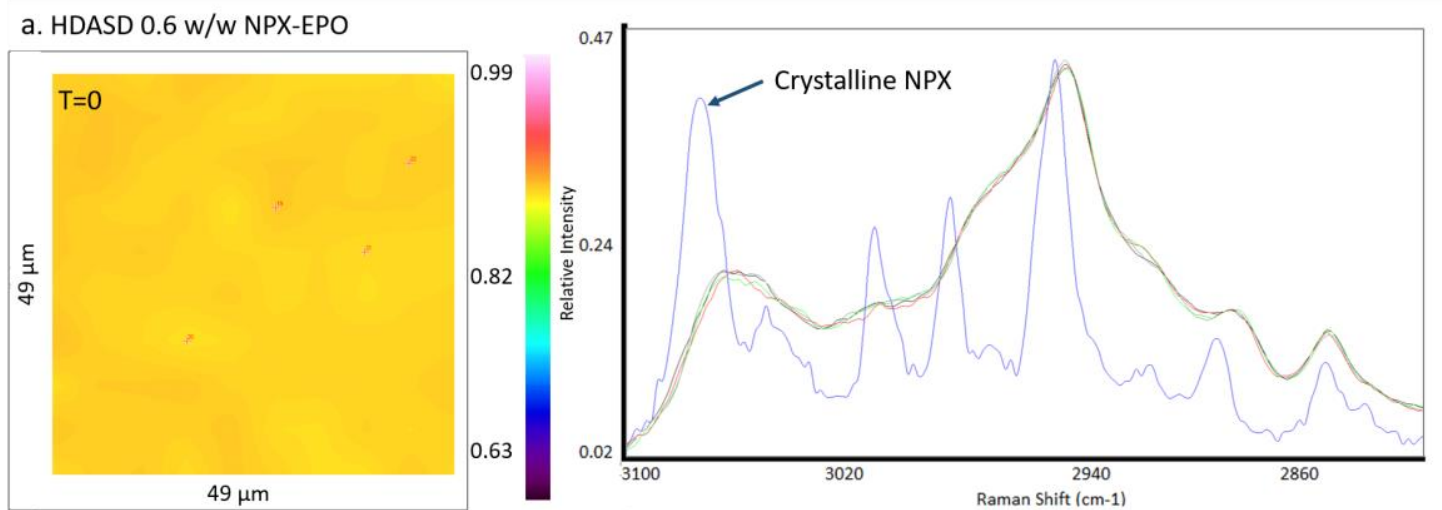

973
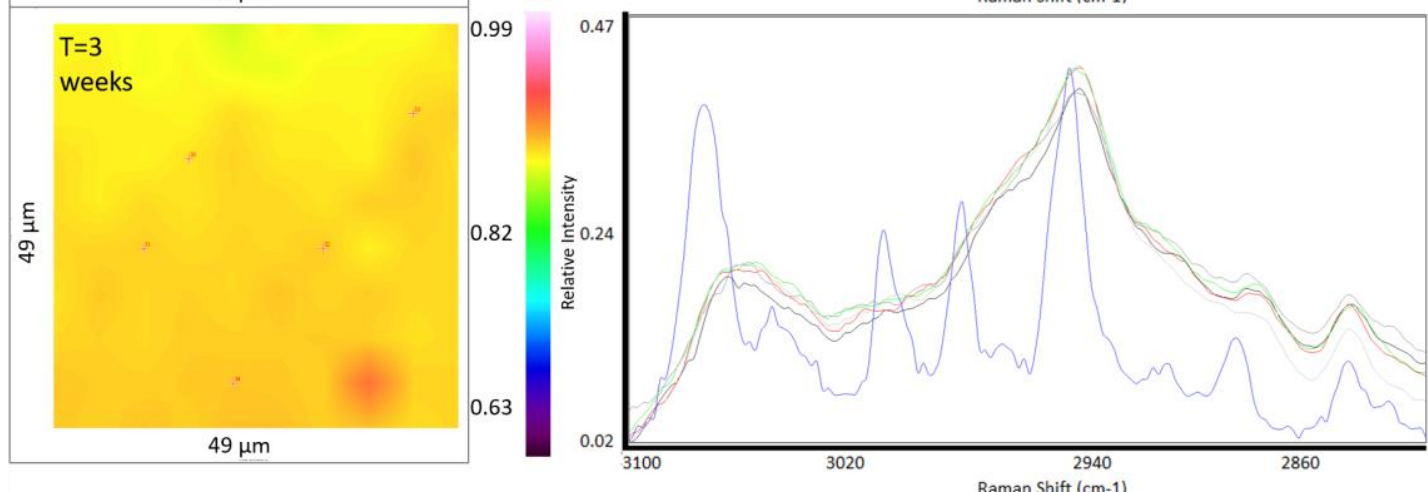

b. HDASD 0.6 w/w IND-EPO
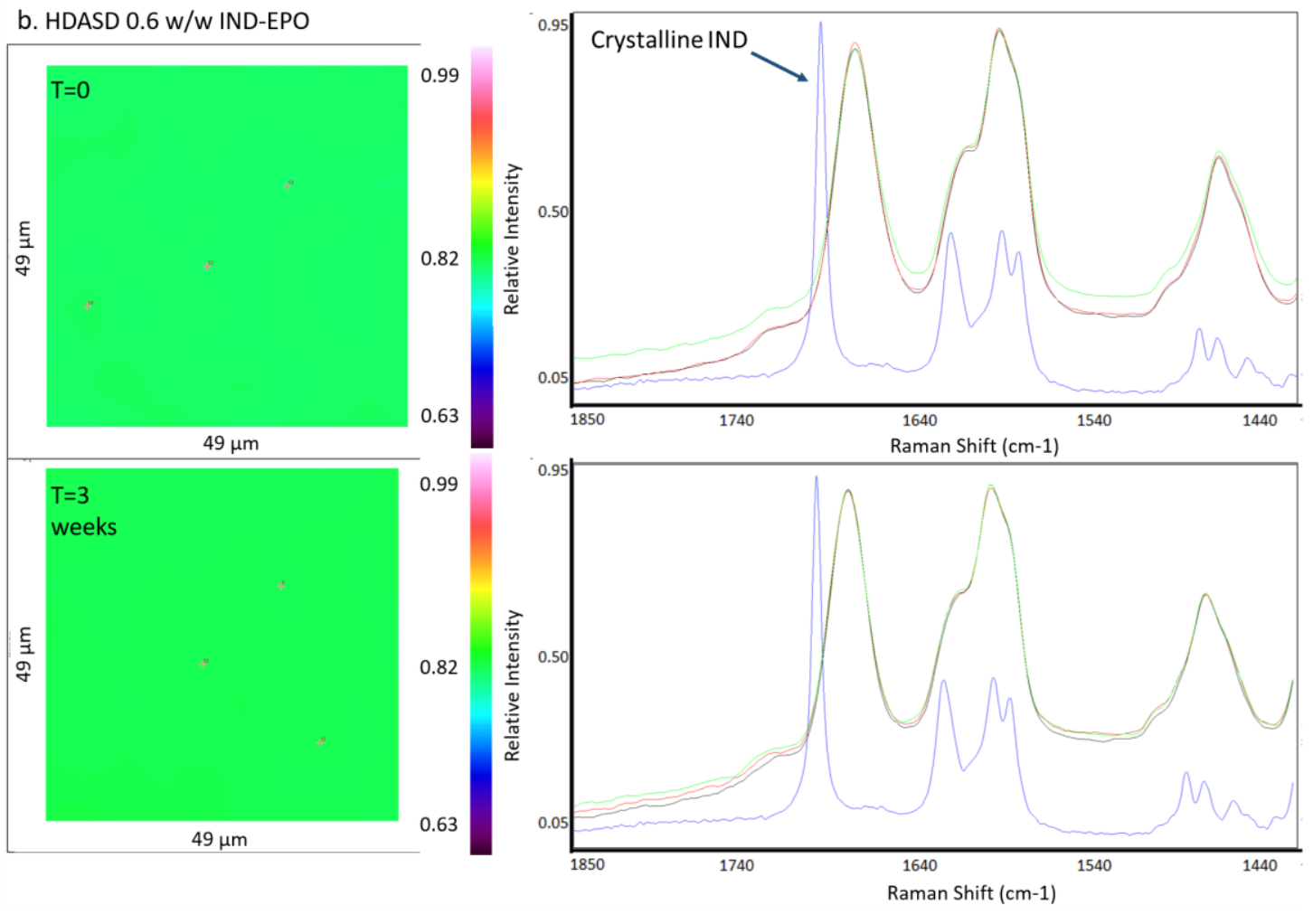
C. HDASD $0.6 \mathrm{w} / \mathrm{w}$ IBU-EPO
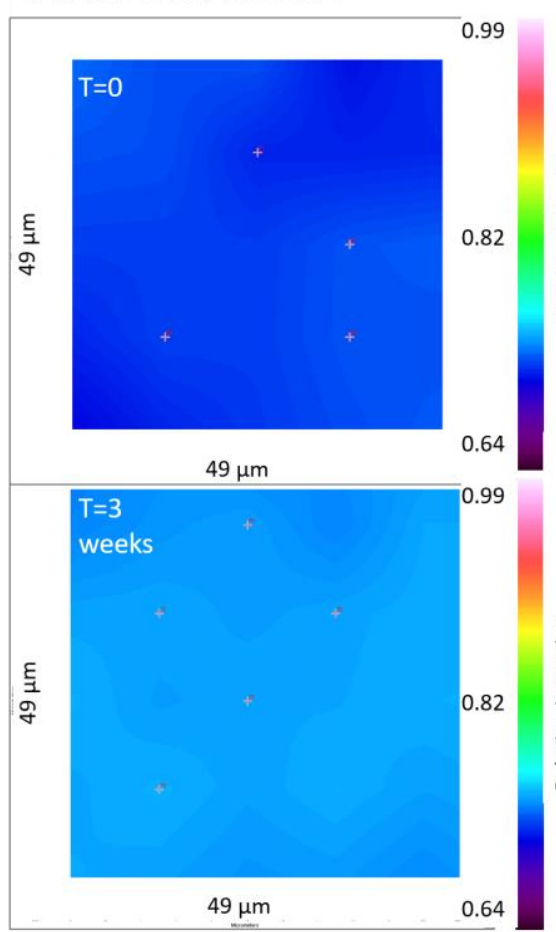

976

977 of $0.7 \mathrm{w} / \mathrm{w}$
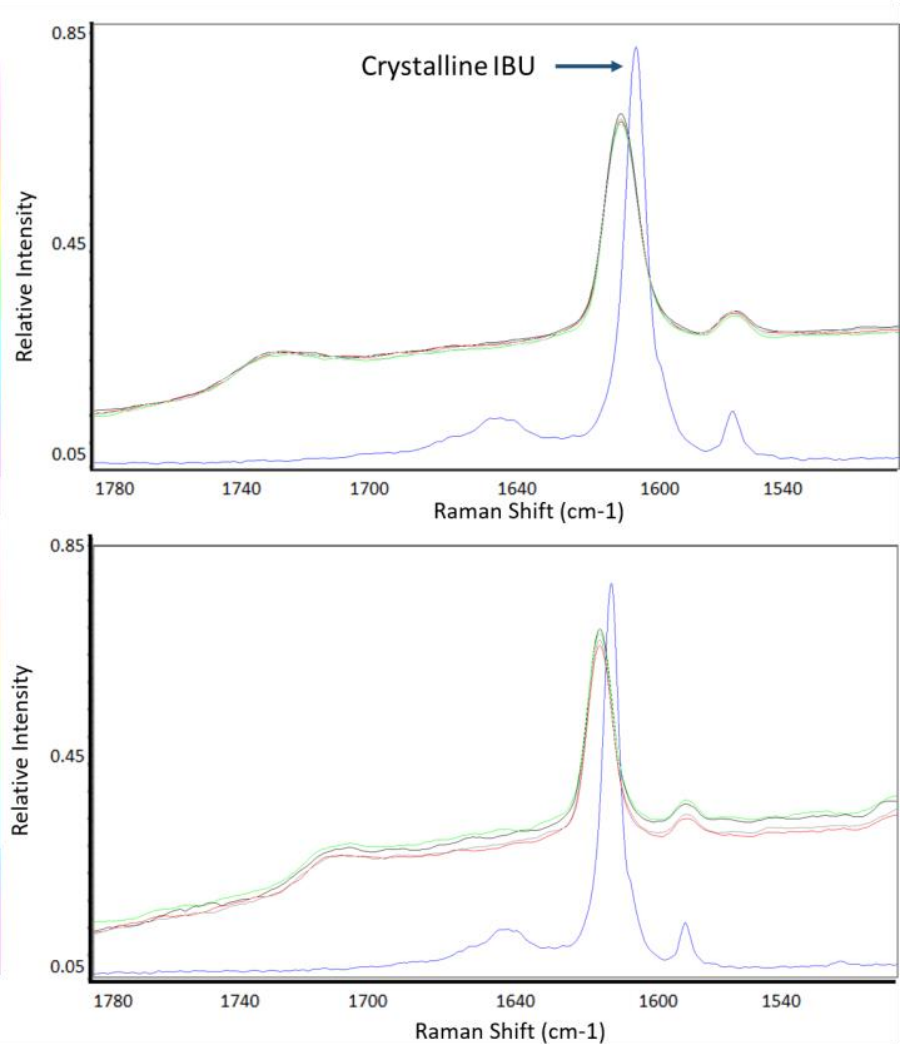

Figure 1chemical structure of polymer Eudragit ${ }^{2}$ EPO (a) and drug indomethacin (b) naproxen (c) ibuprofen (d), reported potential strong drug-polymer intermolecular interactions are highlighted in circles

Figure 2 Evolution of WAXS scattering profiles as a function of sample temperature for physical mixtures IND-EPO (a), NPX-EPO (b) and IBU_EPO (c) at drug loading

Figure 3 The WAXS and SAXS scattering plots for $0.5 \mathrm{w} / \mathrm{w}$ IBU-EPO physical mixture processed via ball-milling at $15 \mathrm{~Hz}$ for 10 minutes

Figure 4 Example of melting point depression thermograms for IND-EPO ball-milled physical mixtures, compositions from 1 to $0.75 \mathrm{w} / \mathrm{w}$.

Figure 5 Plots of Flory-Huggins interaction parameters versus temperature for INDEPO, NPX-EPO and IBU-EPO systems showing Lower Critical Solution Temperature behaviour with $B<0, A>0$ (LCST, at high temperature range)

Figure 6 the temperature-composition phase diagram for systems IND-EPO (a), NPXEPO (b) and IBU-EPO (c) with associated errors; the calculated spinodal curves are shown in dash lines; the experimental and theoretical glass transition temperatures for these HDASDs are also included; EXT and $(X)$ denoted the extrusion conditions 
1000

1001

1002

1003

1004

1005

1006

1007

1008

1009

1010

1011

1012

1013 Figure 10 IR spectra of NPX and EPO mixtures prepared by HME (solid) and quench-

1014 cooled method (dashed) at the regions of carbonyl region (a) and $C-N(b)$

1015 Figure 11 Atomic force microscopic images of NPX-EPO extrudates containing 0.45, 1016 1017

1018

1019

1020

1021

1022

1023

1024

1025

Figure 7 Schematic phase diagrams for various kinds of crystalline-amorphous polymer blends. The binodal and melting point are drawn by solid line (partially by dashed line) and spinodal curves are drawn by dotted lines; red dot illustrates the temperature and drug loading for a stable ASD from both thermodynamic and kinetic perspectives.

Figure 8 IR spectra of IBU-EPO mixtures prepared by HME (solid) and quenchcooled melt (QCPM, dashed) compared with pure crystalline drug and pure EPO polymer

Figure 9 IR spectra of IND-EPO mixtures prepared by HME (solid) and quench-cooled method (QCPM, dashed) in comparison to the crystalline IND 0.60 and $0.65 \mathrm{w} / \mathrm{w}$ drug loadings collected in both topography $(a, b, c)$ and phase contrast modes $(d, e, f)$; the root mean square surface roughness of the extrudates containing various drug loadings for systems NPX-EPO (g) and IND-EPO (h).

Figure 12 microRaman chemical maps and spectra $(49 x 49 \mu$ m, pixel size 1.25 $\mu \mathrm{m} /$ pixel) of HDASDs containing $0.6 \mathrm{w} / \mathrm{w}$ NPX (a) $0.6 \mathrm{w} / \mathrm{w}$ IND (b) and $0.6 \mathrm{w} / \mathrm{w}$ $I B U(c)$ before and after three-week storage at 95\%RH, the spectra for crystalline drugs are highlighted using the black arrows. 